\title{
Characterizing Nanoparticles in Biological Matrices: Tipping Points in Agglomeration State and Cellular Delivery In Vitro
}

John W. Wills, ${ }^{\dagger}$ Huw D. Summers, ${ }^{*}{ }^{\ddagger}$ Nicole Hondow, ${ }^{\S}$ Aishwarya Sooresh, ${ }^{\|}$Kenith E. Meissner, ${ }^{\perp, \#}$ Paul A. White, ${ }^{\mathbb{T}}$ Paul Rees, ${ }^{\dagger}, \triangle$ Andy Brown, ${ }^{\S}$ and Shareen H. Doak ${ }^{\dagger}$

${ }^{\dagger}$ Institute of Life Sciences, Swansea University Medical School, Singleton Park, Swansea, SA2 8PP, U.K.

${ }^{\ddagger}$ Centre for Nanohealth, Swansea University College of Engineering, Fabian Way, Crymlyn Burrows, Swansea, SA1 8EN, U.K.

${ }^{\S}$ School of Chemical and Process Engineering, University of Leeds, Leeds, LS2 9JT, U.K.

${ }^{\|}$Department of Materials Science and Engineering, Texas A\&M University, College Station, Texas 77843, United States

${ }^{\perp}$ Department of Biomedical Engineering, Texas A\&M University, College Station, Texas 77843, United States

\#Department of Physics, Swansea University College of Science, Singleton Park, Swansea, SA2 8PP, U.K.

${ }^{I}$ Department of Biology, University of Ottawa, 30 Marie-Curie Private, Ottawa K1N 9B4, Ontario, Canada

$\triangle$ Broad Institute of MIT and Harvard, 415 Main Street, Cambridge, Massachusetts 02142, United States

\section{Supporting Information}

ABSTRACT: Understanding the delivered cellular dose of nanoparticles is imperative in nanomedicine and nanosafety, yet is known to be extremely complex because of multiple interactions between nanoparticles, their environment, and the cells. Here, we use 3-D reconstruction of agglomerates preserved by cryogenic snapshot sampling and imaged by electron microscopy to quantify the "bioavailable dose" that is presented at the cell surface and formed by the process of individual nanoparticle sequestration into agglomerates in the exposure media. Critically, using 20 and $40 \mathrm{~nm}$ carboxylated polystyrene-latex and 16 and $85 \mathrm{~nm}$ silicon dioxide nanoparticles, we show that abrupt, dose-dependent "tipping points" in agglomeration state can arise, subsequently affecting cellular delivery and increasing toxicity. These changes are triggered by shifts in the ratio of the total nanoparticle surface area to biomolecule abundance, with the switch to a highly agglomerated state effectively changing the test article midassay, challenging the dose-response paradigm for nanosafety experiments. By characterizing nanoparticle numbers per agglomerate, we show these tipping points can lead to the formation of extreme agglomeration states whereby $90 \%$ of an administered dose is contained and delivered to the cells by just the top $2 \%$ of the largest agglomerates. We thus demonstrate precise definition, description, and comparison of the nanoparticle dose formed in different experimental environments and show that this description is critical to understanding cellular delivery and toxicity. We further empirically "stress-test" the commonly used dynamic light scattering approach, establishing its limitations to present an analysis strategy that significantly improves the usefulness of this popular nanoparticle characterization technique.

KEYWORDS: nanoparticle-biomolecule interactions, agglomeration state, transmission electron microscopy, dynamic light scattering, dosimetry, nanotoxicology, nanomedicine
$\mathrm{E}$ ngineered nanomaterials (ENMs) have the potential to revolutionize areas of biomedicine as diverse as cancer therapeutics, antimicrobials, and medical imaging., However, to achieve these goals, there remains a huge unmet need to enable translational research through improvement of our understanding of nanoparticle-biomolecule interactions and their consequences in terms of the nanoparticle dose that arrives at the cells. The issue is that even when ENMs are synthesized in a de novo form that successfully achieves a desired behavior, they become modified upon introduction to biological environments through interaction with proteins and other biological components. According to availability and

Received: May 26, 2017

Accepted: October 26, 2017

Published: October 26, 2017 
affinity, biomolecules bind onto the surfaces of nanoparticles, resulting in the formation of a protein corona that modulates surface properties, chemistry, and charge. ${ }^{3-5}$ In turn, these modifications influence the attractive and repulsive forces operating between nanoparticles in solution, shaping their potential to collide and form agglomerates. Collectively, these processes alter the administered dose, leading to the establishment of a "bioavailable dose" under experimental and/or physiological conditions. Unsurprisingly, this has consequences for the therapeutic efficacy and toxicity profile of the nanoparticles that arrive at the cells. ${ }^{6,7}$

The potential for nanoparticle exposures to cause adverse effects, alongside the increasing incorporation of potentially hazardous ENMs into consumer products, necessitates reliable, high-throughput in vitro assays for nanosafety screening. ${ }^{6,8}$ However, despite the dramatic increase in nanosafety research conducted across the past decade, few unequivocal answers regarding the physical and chemical properties of ENMs that govern toxicity have been found. ${ }^{9,10}$ Furthermore, attention is increasingly becoming focused on the often contradictory results of similar in vitro studies or corresponding in vitro and in vivo assessments. ${ }^{6,11}$ These conflicting findings are thought to be partially attributable to insufficient ENM characterization in the biological matrix of the employed test system, where the aforementioned processes of serum protein-to-particle binding and agglomeration modify the characteristics of the administered dose prior to cellular delivery. ${ }^{3,6,12}$ Consequently, there is an urgent need to provide robust biological characterization data to support, interpret, and translate toxicological findings. It is realized however that current techniques may be insufficient to define the bioavailable dose (e.g., when heterogeneous agglomeration states are formed or the test article is present at low concentration in a "complex" environment such as serumcontaining cell growth medium). ${ }^{9}$ New methods for nanoparticle characterization in relevant physiological environments are therefore required to accurately establish exposure during nanosafety assessments ${ }^{13-15}$ as well as to improve the efficacy and biocompatibility of newly developed nanomedicines. ${ }^{4,7}$

Nanoparticle agglomeration is most commonly characterized by dynamic light scattering (DLS). This technique works by passing laser light through a solution and correlating the light scatter caused by particulates to their size. ${ }^{16}$ Whereas DLS constitutes a robust method for the assessment of "narrow", monodisperse particulate size distributions, it is known to become much less reliable as particulate sizes become increasingly varied and polydisperse. This occurs intrinsically as the intensity of the scattered light is proportional to the sixth-power of the scattering particulate's diameter (i.e., $I_{\mathrm{sc}} \propto$ $\left.d^{6}\right)$. A direct consequence of this relationship is that the light scatter from smaller particulates in a solution quickly becomes overwhelmed by the scatter signature of any large particulates, even if the latter are present at extremely low frequency. ${ }^{17-19}$ Another limitation of DLS is that it is not able to directly distinguish different types of particulates on the basis of composition. ${ }^{20}$ In biological matrices, this means that the light scatter from serum biomolecules and other biological components-in addition to that of the target nanoparticles-all contribute to the size measurements obtained. ${ }^{21}$ For these reasons it has become common practice to carry out DLS analysis using just the highest dose tested in a nanosafety study, as this maximizes the signal from the target nanoparticles relative to the background signal from biological molecules. In turn, these characterizations at "top dose" are typically assumed to be representative for the complete set of exposure concentrations employed in a toxicological dose-response assay. $^{22-26}$

To address the limitations of DLS for the characterization of nanoparticle dispersions in biological environments, several studies have employed cryogenic plunge freezing and transmission electron microscopy (TEM) as an alternative technique for the characterization of agglomeration states. ${ }^{20,27}$ This approach relies upon freezing a sample of the nanoparticle dispersion with sufficient speed such that the liquid phase vitrifies without significant reorganization of dispersed material. ${ }^{20}$ To date, this technique has been used to study the aggregation of biological molecules ${ }^{28}$ and polymeric dendrimers, ${ }^{29}$ as well as to characterize the agglomeration states of quantum $\operatorname{dot}^{20}$ and zinc oxide ${ }^{27}$ nanoparticles in cell culture media. Critically, this approach circumnavigates the limitations of "drop-cast" TEM samples whereby a drop of the nanoparticle dispersion is allowed to air-dry on a TEM grid prior to imaging. Whereas samples prepared in this manner are suitable for the characterization of the size, shape, and composition of individual particles (i.e., primary particle characterization), they are not an informative or reliable assessment of agglomeration, as the particulates present are known to aggregate together as the liquid phase recedes during evaporation. ${ }^{20,30}$ It has been shown however that samples prepared by cryogenic plunge freezing can be warmed under high vacuum, enabling sublimation of the liquid phase without disruption of the state of the suspended material. ${ }^{20}$ Thus, this approach yields stable, room-temperature samples that are suitable for imaging and determination of agglomeration state by routine, high-resolution $(<1 \mathrm{~nm})$ bright-field TEM. Importantly, this "cryogenic snapshot sampling" (CSS) approach can facilitate the collection of large image sets when compared to the relative complexity of imaging under full cryogenic conditions. However, a major limitation of all studies employing TEM for agglomeration state characterization to date remains that the data obtained are 2-D, cross-sectional images of what are ultimately 3-D, agglomerated particulates. In particular, this places limitations on understanding exactly how the administered dose is transformed into the bioavailable dose presented to the cells by the process of individual particle sequestration into agglomerates.

To this end, here we use 3-D image reconstruction of cryogenic snapshot sampled agglomerates to calibrate the number of nanoparticles per agglomerate, permitting precise definition, description, and comparison of the bioavailable doses established in different biological environments. Importantly, we show that shifts in the ratio of the administered dose to serum biomolecule abundance can trigger abrupt "tipping points" in agglomeration state that dramatically affect cellular delivery and subsequent toxicity, challenging the doseresponse paradigm for nanosafety assessments. We further use the CSS-TEM results to thoroughly "stress-test" the commonly used DLS method, pinning down its limitations once and for all to provide an analysis strategy that significantly improves the usefulness of this popular, high-throughput technique.

\section{RESULTS/DISCUSSION}

This study used 20 and $40 \mathrm{~nm}$ carboxylate surface-modified polystyrene-latex (PS) and 16 and $85 \mathrm{~nm}$ silicon dioxide $\left(\mathrm{SiO}_{2}\right)$ nanoparticles to study the consequences of nanoparticle agglomeration in terms of the dose of nanoparticles delivered to human B lymphoblastoid cells (TK6). The TK6 cells were 

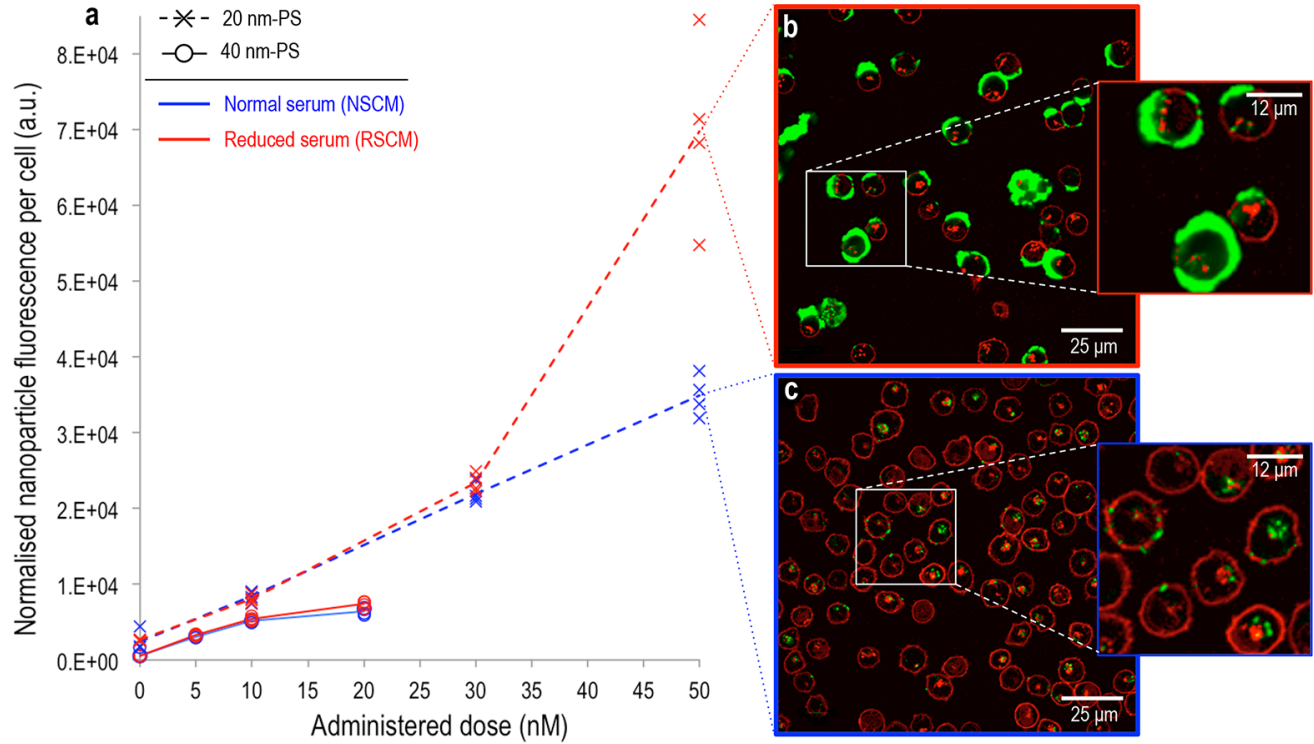

Figure 1. Tipping points in nanoparticle agglomeration. (a) Average cellular delivery (normalized fluorescence, proportional to particle number per cell) of $20 \mathrm{~nm}$ (crosses) and $40 \mathrm{~nm}$ (circles) polystyrene-latex (PS) nanoparticles to TK6 cells grown in normal (NSCM, blue) or reduced (RSCM, red) serum containing media measured by imaging cytometry after $24 \mathrm{~h}$ exposure $(5000$ cells per replicate; $n=4)$. $(\mathrm{b} / \mathrm{c})$ Fluorescence micrographs $($ red $=$ cell membrane, green $=$ nanoparticles $)$ obtained as optical sections by confocal microscopy showing the increase in cellular dose seen specific to the $20 \mathrm{~nm}$ PS/50 nM dose/RSCM combination (b) was caused by a dramatic increase in the quantity of nanoparticles binding to the outsides of the cells.

Table 1. PS Nanoparticle Agglomeration State and Surface Charge (Zeta Potential) Characterization by Dynamic Light Scattering across Dose and Serum Environments (NSCM/RSCM = Normal/Reduced Serum Containing Media) Using the Cumulants (“Z-Average”) Analysis Approach ${ }^{a}$

\begin{tabular}{|c|c|c|c|c|c|}
\hline Nanoparticle: & $\begin{array}{c}\text { Administered } \\
\text { dose: }\end{array}$ & Dispersant: & $\begin{array}{c}\text { Agglomeration state: } \\
\text { Z-average } \\
\text { hydrodynamic diameter, } \\
\text { nm } \\
\text { Size } \pm \text { SD }\end{array}$ & $\begin{array}{l}\text { Surface charge: } \\
\text { Zeta potential, mV } \\
\text { ZP } \pm \mathrm{SD}(p H)\end{array}$ & $\begin{array}{l}\text { Polydispersity } \\
\text { index: }\end{array}$ \\
\hline \multirow{6}{*}{$20 \mathrm{~nm}-\mathrm{PS}$} & \multirow{3}{*}{$10 \mathrm{nM}$} & Water & $63.7 \pm 1.1$ & $-59.2 \pm 3.2(5.8)$ & $0.2-0.3$ \\
\hline & & NSCM & $46.8 \pm 0.5$ & $-2.1 \pm 0.5(7.2)$ & $0.4-0.6$ \\
\hline & & $\mathrm{RSCM}$ & $125.4 \pm 1.1$ & $-8.7 \pm 0.8(7.2)$ & $0.2-0.3$ \\
\hline & \multirow{3}{*}{$50 \mathrm{nM}$} & Water & $67.2 \pm 0.9$ & $-63.2 \pm 4.1(5.2)$ & $0.1-0.2$ \\
\hline & & NSCM & $105.8 \pm 2.6$ & $-8.1 \pm 0.8(7.2)$ & $0.2-0.3$ \\
\hline & & RSCM & $650.1 \pm 40.3$ & $-9.5 \pm 0.3(7.2)$ & $0.55-0.64$ \\
\hline \multirow{3}{*}{$40 \mathrm{~nm}-\mathrm{PS}$} & \multirow{3}{*}{$10 \mathrm{nM}$} & Water & $78.7 \pm 1.5$ & $-50.4 \pm 8.3(4.5)$ & $0.1-0.2$ \\
\hline & & NSCM & $83.3 \pm 2.1$ & $-13.3 \pm 0.9(7.2)$ & $0.2-0.3$ \\
\hline & & RSCM & $84.0 \pm 1.9$ & $-17.4 \pm 0.9(7.2)$ & $0.2-0.3$ \\
\hline
\end{tabular}

${ }^{a}$ A dramatic increase in agglomerate size was indicated for the $50 \mathrm{nM}$ dose of $20 \mathrm{~nm}$ PS in RSCM, but the accompanying polydispersity index (PdI) was above the reliability threshold for cumulants-based analysis (indicated, red).

chosen because their use is supported by the current Organisation for Economic Co-operation and Development (OECD) micronucleus assay test guideline ${ }^{31}$ (i.e., TG 487); thus, they represent a widely employed cell line that has been extensively validated for carrying out this "gold-standard" assay for the detection of xenobiotic-induced DNA damage. Before beginning the cell experiments, the manufacturer-supplied stock nanoparticle solutions underwent thorough physicochemical characterization (summarized in full in Table S1). Briefly, TEM was used to define size distributions and showed that all nanoparticles were smooth and spherical and possessed amorphous chemical structures. Energy dispersive X-ray
(EDX) analysis confirmed expected elemental compositions and, importantly for the subsequently presented toxicity results, ruled out the presence of any contaminants (TEM and EDX results presented in Figure S1). Analysis by DLS (Table S1, subsequently presented in full) further showed that stock nanoparticle solutions were monodisperse and possessed the high net-negative surface charges expected because of the carboxylated surface chemistries of the PS nanoparticles and unbound surface oxygen groups of the $\mathrm{SiO}_{2}$ nanoparticles.

In studying nanoparticle delivery to the cells, the PS nanoparticles were employed first as they constituted an excellent model: they are readily internalized by the cells 

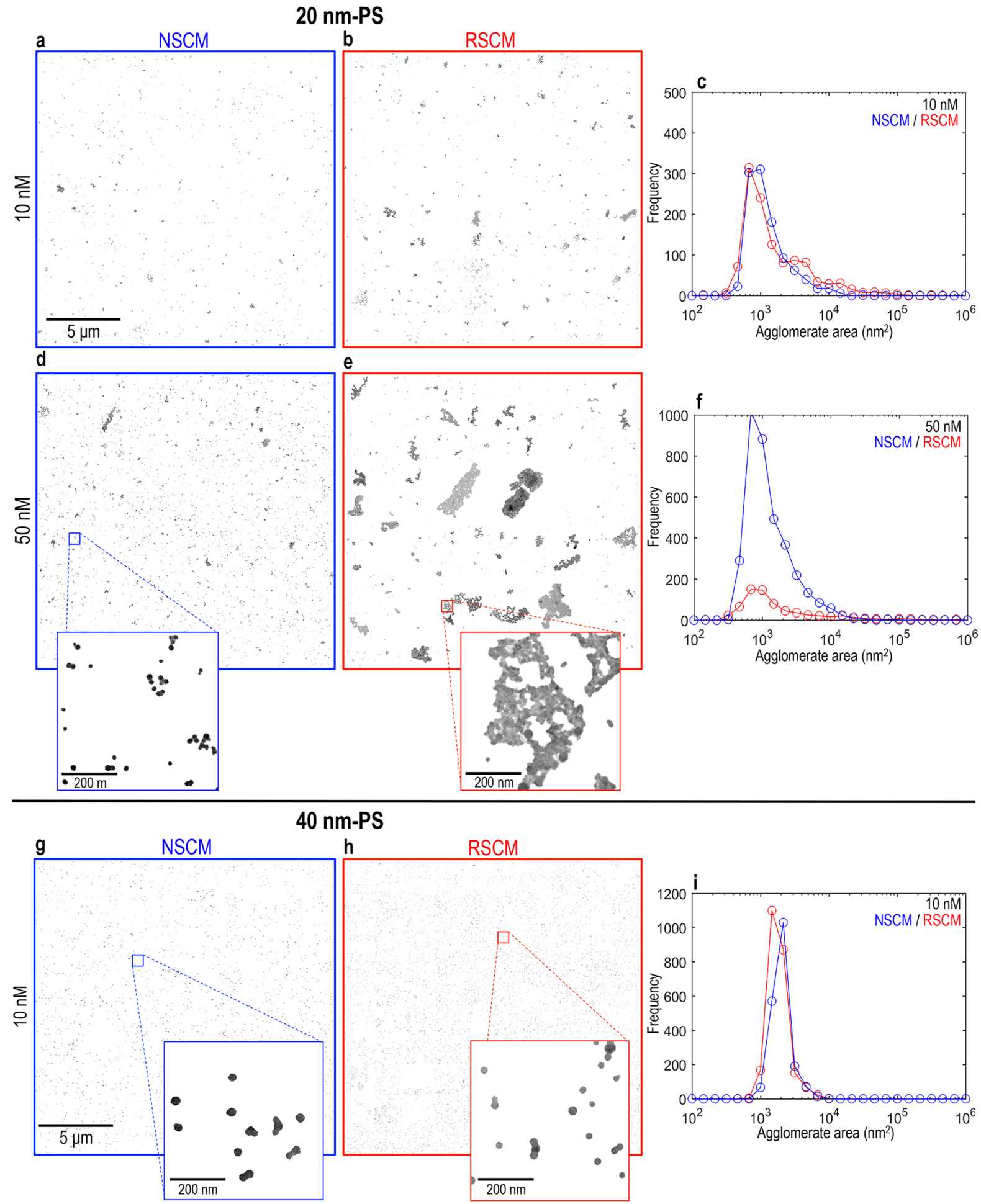

Figure 2. Characterizing PS nanoparticle agglomeration state using cryogenic snapshot sampling and transmission electron microscopy (CSSTEM). Tiled electron micrographs (a/b/d/e, $20 \mathrm{~nm}$ PS; g/h, $40 \mathrm{~nm}$ PS) from the CSS-TEM studies showing nanoparticle agglomeration states $1 \mathrm{~h}$ after dose administration at 10 or $50 \mathrm{nM}$ in normal (NSCM, blue) or reduced (RSCM, red) serum containing media (150 micrographs yielding $\sim 1300-5000$ agglomerates per sample). The change in cellular delivery observed optically (Figure $1 \mathrm{~b})$ for the $50 \mathrm{nM}$ dose of $20 \mathrm{~nm}$ PS in RSCM is seen to coincide with an abrupt change (e) to much larger agglomerates. (c/f/i) Agglomerate area distributions constructed by image analysis of the CSS-TEM data.

(Figure S2), produce a stable fluorescence intensity (Figure S3), are nontoxic to the cells, permitting accurate quantification of the full range of delivered cellular doses after exposure (Figure S4), and are neutrally buoyant (density $=1.05 \mathrm{~g} / \mathrm{cm}^{3}$ ), minimizing sedimentation and optimizing delivery to the suspended-cell population. Subsequently, the $\mathrm{SiO}_{2}$ nanoparticles were used, as they represent a commonly tested nanosafety test material due to exposure concerns arising from their incorporation in polishes, adhesives, varnishes, and photocopier toner and their use as food-stabilizing agents and 

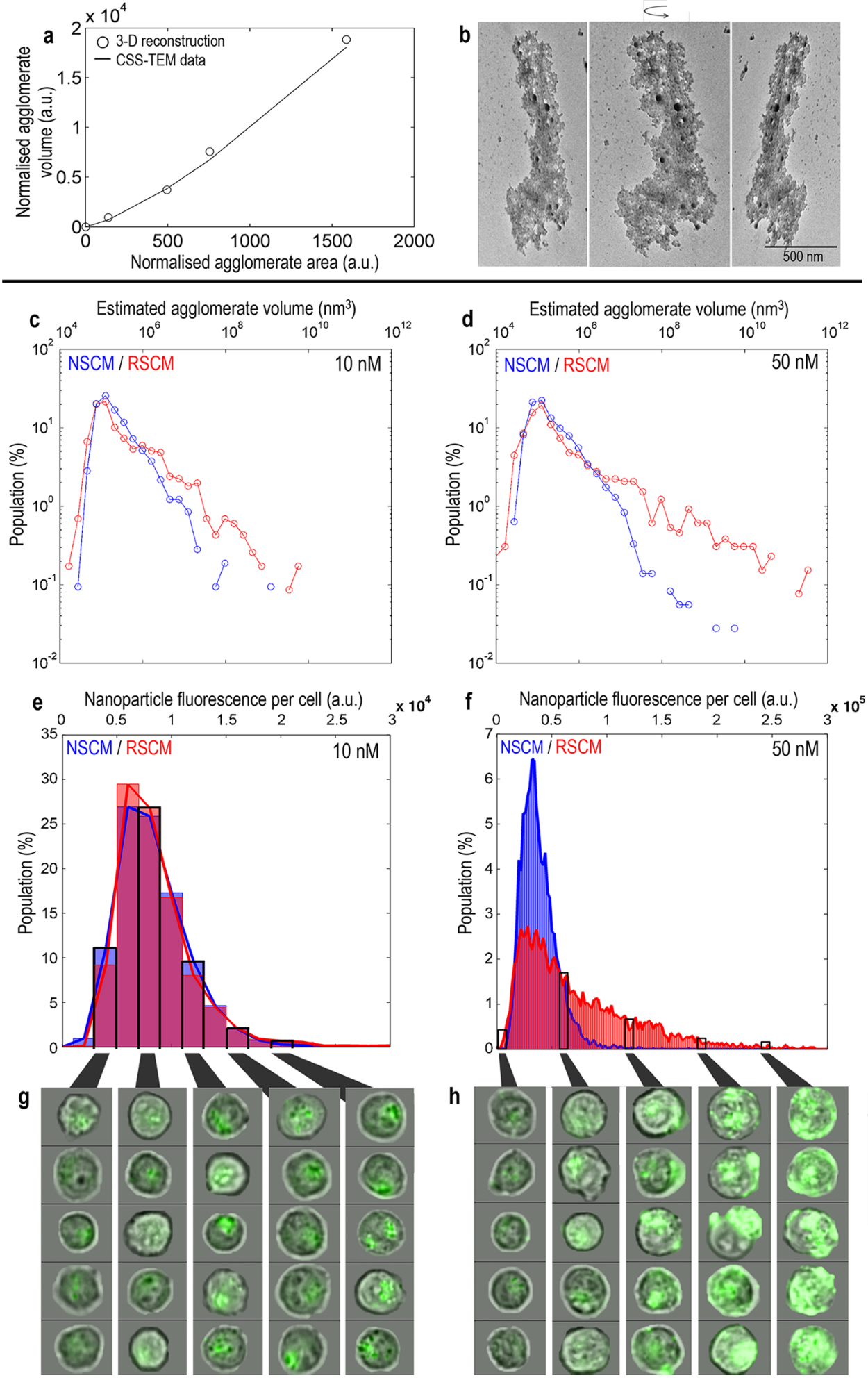

Figure 3. Modulation of the delivered cellular dose of $20 \mathrm{~nm}$ PS nanoparticles by agglomeration. (a/b) The areas and volumes of five agglomerates of varying size were measured by rotation (b) using electron micrographs collected by $\sim 100$ image tilt-series experiments (see Video S1 for full resolution view). (a) These measured data (circles) empirically validate the scaling model used to transform the 2-D CSSTEM agglomerate area data into estimated agglomerate volume (line = transformed CSS-TEM data). (c/d) Estimated agglomerate volume distributions obtained by applying the scaling model to the 2-D CSS-TEM data for administered nanoparticle doses of 10 or $50 \mathrm{nM}$ in normal (NSCM, blue) or reduced (RSCM, red) serum containing media. (e/f) Cellular fluorescence distributions, linearly related to the volume of the nanoparticle dose per cell, (i.e., directly comparable to $\mathrm{c} / \mathrm{d}$ ) constructed from the combined imaging cytometry data shown in Figure 1a (histograms with overlaid outlines). Below the distributions $(\mathrm{g} / \mathrm{h})$, sample fluorescence micrographs (green $=$ nanoparticles) from the cytometer corresponding to the indicated intensity bins are shown. Cell-to-cell variability in the delivered dose (e/f) increased dramatically with increasing agglomerate size heterogeneity $(\mathrm{c} / \mathrm{d})$. 

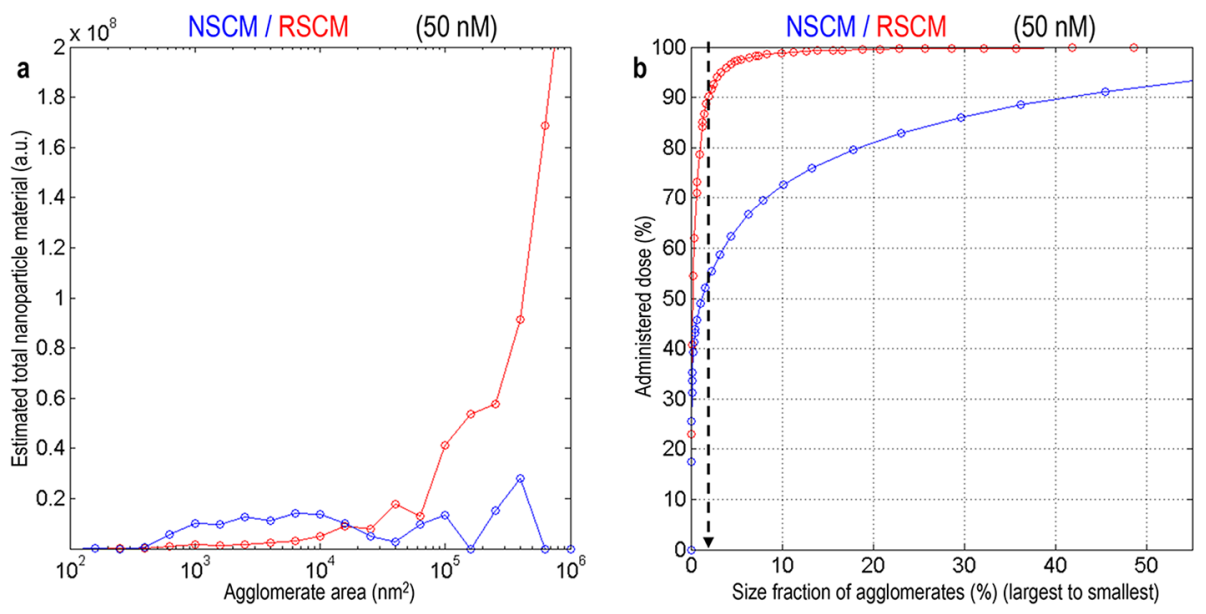

Figure 4. Transformation of the $50 \mathrm{nM}$ administered dose of $20 \mathrm{~nm}$ PS by nanoparticle agglomeration. (a) Estimated total amount of nanoparticle material present at each agglomerate size in normal (NSCM, blue) or reduced (RSCM, red) serum containing media calculated as the product of agglomerate population percentage and agglomerate volume. (b) Cumulative distribution function of the administered dose in each serum environment, proceeding from the largest to the smallest size fraction of agglomerates. The arrow indicates that $\sim 90 \%$ of the 50 $\mathrm{nM}$ administered dose was sequestered into just the top 2\% size-fraction of largest agglomerations in RSCM, whereas in NSCM, only 50\% of the administered dose was contained within this same agglomerate size-fraction.

cosmetic additives. ${ }^{32,33}$ Critically, they also represent a nanoparticle type that has produced conflicting results when the findings of similar in vitro studies or corresponding in vitro and in vivo assessments have been compared. ${ }^{32}$

As serum concentration is dynamic in vivo ${ }^{34-36}$ and the concentration of supplemental serum used in vitro is known to affect nanosafety test outcomes, the use of more than one concentration during nanosafety hazard assessment has been recommended. ${ }^{37-40}$ We therefore began by evaluating the cellular delivery of the PS nanoparticles in either normal (10\%) (NSCM) or reduced (2\%) (RSCM) serum containing cell culture media.

Characterizing Cellular Delivery and 2-D Agglomeration State. Using high-throughput imaging cytometry, the delivered cellular dose of 20 or $40 \mathrm{~nm}$ PS nanoparticles after 24 $\mathrm{h}$ of exposure in the NSCM or RSCM serum environments is shown in Figure 1a. For both the $20 \mathrm{~nm}$ and $40 \mathrm{~nm}$ PS, this increases more or less linearly, as expected, and is independent of serum environment over the 0-30 $\mathrm{nM}$ dose range. Interestingly, however, the $20 \mathrm{~nm}$ PS exposure at $50 \mathrm{nM}$ in RSCM resulted in a marked, nonlinear increase in cellular dose. Confocal microscopy (Figure $1 \mathrm{~b} / \mathrm{c}$ ) showed this change was caused by a dramatic increase in the quantity of nanoparticles binding to the outside of the cells relative to those internalized (further confocal micrographs for all nanoparticle/serum combinations presented in Figure S5). In an effort to understand why this sudden transformation occurred, DLS was used to assess nanoparticle agglomeration states and surface charges (Table 1). The results proved difficult to interpret however since there was little concurrency in $20 \mathrm{~nm}$ PS size measurements across serum environments, even for the $10 \mathrm{nM}$ doses that showed highly similar cellular delivery in both media types. A dramatic increase in agglomerate size $(\sim 650$ $\mathrm{nm})$ relative to all other $20 \mathrm{~nm}$ PS measurements $(<125 \mathrm{~nm})$ was indicated by DLS for the $50 \mathrm{nM}$ dose in RSCM, but the accompanying polydispersity index (PdI) was high enough $(0.61)$ to suggest a heterogeneous size distribution unsuitable for this type of averaged, cumulants-based analysis. ${ }^{41}$ Thus, as these " $Z$-average" DLS results-which are typical of those often employed by nanosafety studies-were of questionable utility for providing further insight into the findings of the delivered dose study, the state of PS nanoparticle agglomeration was further investigated using cryogenic snapshot samplingtransmission electron microscopy (CSS-TEM) and image analysis $^{20}$ (method explained in Figure S6).

At administered doses of $10 \mathrm{nM}$, the $20 \mathrm{~nm}$ PS agglomeration states captured by CSS-TEM across the NSCM and RSCM environments were visually very similar (Figure $2 \mathrm{a} / \mathrm{b}$ ), and the resultant size distributions of agglomerate area produced by image analysis were nearly identical (Figure 2c). In contrast, the $20 \mathrm{~nm}$ PS agglomeration states established from administered doses of $50 \mathrm{nM}$ were seen to markedly differ across serum environments (Figure $2 \mathrm{~d} / \mathrm{e}$ ) with large, sparsely distributed agglomerates forming in RSCM in a manner specific to this dose and serum combination (Figure 2e). Interestingly, however, this visually striking change to larger agglomerates in RSCM is not immediately apparent in the comparison of the area size distributions (Figure $2 \mathrm{f}$ ). Here, the size distribution in RSCM appears anomalous because of a low quantity of agglomerates present, not because of an increase in agglomerate size, as is visually expected. In keeping with the findings of the delivered cellular dose (Figure 1) and DLS studies (Table 1), CSS-TEM-based comparisons of the $40 \mathrm{~nm}$ PS show agglomeration states established from $10 \mathrm{nM}$ administered doses across serum environments were highly similar (Figure $2 \mathrm{~g}-\mathrm{i}$ ).

3-D Agglomerate Characterization Sheds Light on Delivery Heterogeneity. When considering the size distributions presented by agglomerate area in Figure 2, it is important to note that these were constructed using 2-D crosssectional image information without taking into account the true 3-D geometry of each agglomerate. This is of importance, as this $2-\mathrm{D}$ view presents an impediment to understanding exactly how the dose administered is transformed into the bioavailable dose presented to the cells by the sequestering of individual nanoparticles into 3-D agglomerates. Thus, to obtain a more complete description of how identical, $50 \mathrm{nM}$ administered doses of $20 \mathrm{~nm}$ PS established such different bioavailable doses across serum environments, the crosssectional area data were transformed using a power law 

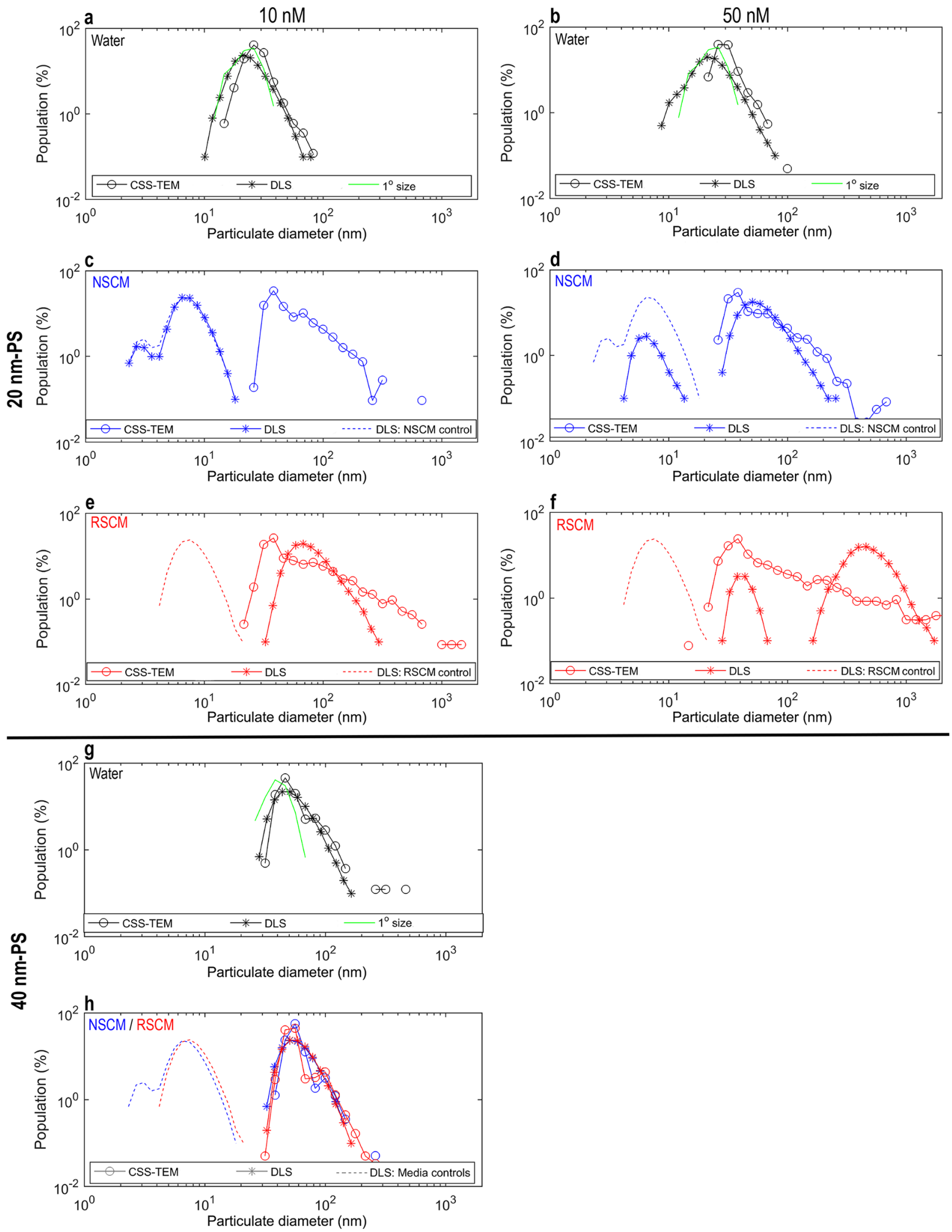

Figure 5. DLS stress-testing: $20 \mathrm{~nm}$ PS and $40 \mathrm{~nm}$ PS agglomerate hydrodynamic size distributions by number (stars) were extracted from the DLS study (Table 1) and compared to agglomerate Feret diameter measurements directly measured by CSS-TEM (circles). (a/b/g) For the results collected using water as a dispersant (i.e., in "as-manufactured" dispersant), primary size distributions of individually measured nanoparticle diameters obtained from drop-cast TEM micrographs were also included (green lines) to provide a point of reference for the size of individual nanoparticles relative to agglomerates (i.e., primary size controls). Size distributions were measured $1 \mathrm{~h}$ after dose administration at $10 \mathrm{nM}($ left; a/c/e/g/h) or $50 \mathrm{nM}$ (right; b/d/f) in water (black), normal (NSCM, blue), or reduced (RSCM, red) serum containing media. DLS size distributions for the NSCM and RSCM alone (dashes) were included as media controls to ensure that the target nanoparticles were reliably detected against the light-scattering background of serum molecules. 

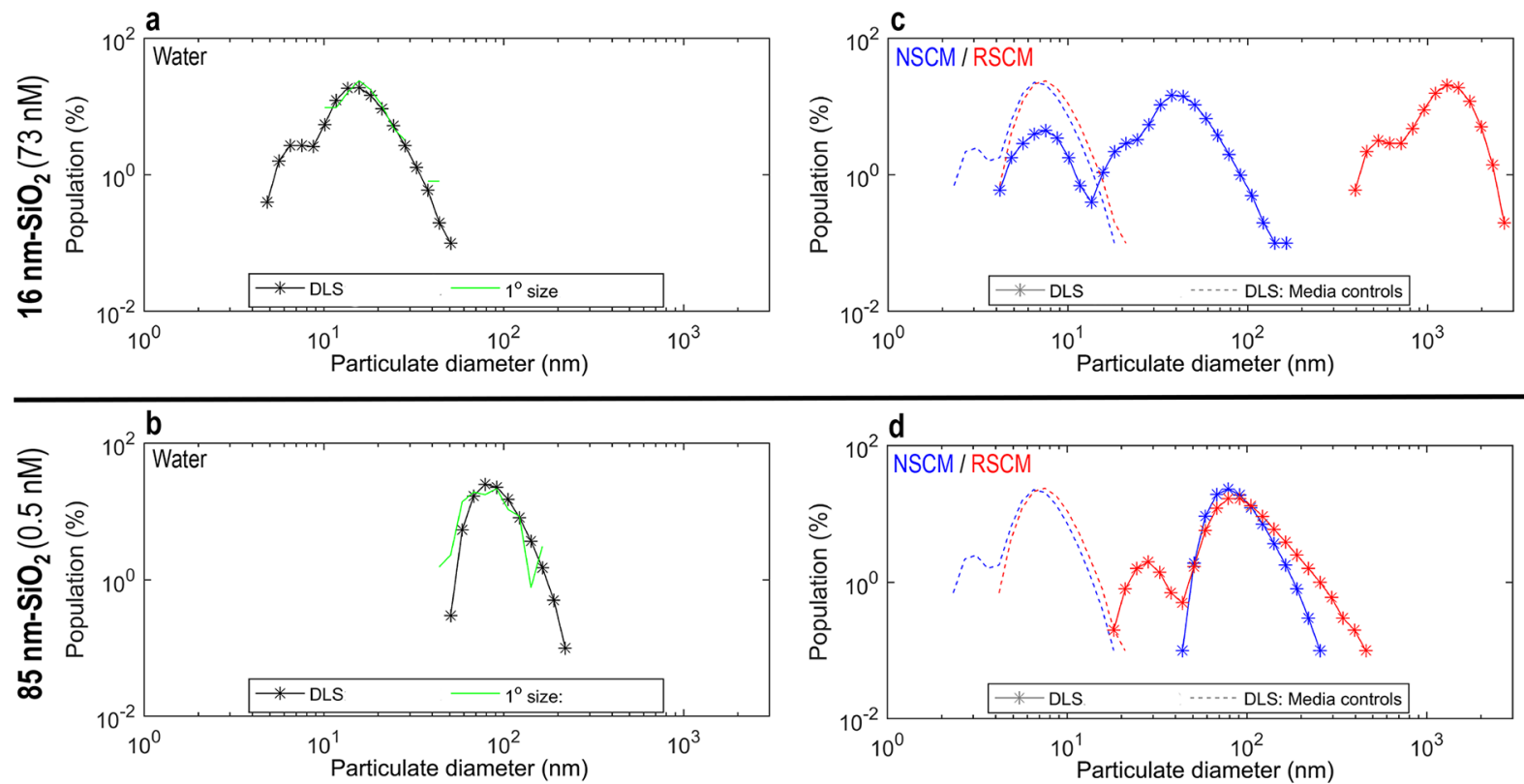

Figure 6. Using DLS alone to detect abnormal agglomeration states: BASF Levasil silicon dioxide nanoparticles $\left(\mathrm{SiO}_{2}\right) .(\mathrm{a} / \mathrm{c}) 16 \mathrm{~nm} \mathrm{SiO}{ }_{2}$ and (b/d) $85 \mathrm{~nm} \mathrm{SiO} 2$ hydrodynamic size distributions by number (stars) were extracted from the DLS studies. (a/b) For the results collected using water as a dispersant (i.e., in "as-manufactured" dispersant), primary size distributions of individually measured nanoparticle diameters obtained from drop-cast TEM micrographs were also included (green lines) to provide a point of reference for the size of individual nanoparticles relative to agglomerates (i.e., primary size controls). Size distributions were measured $1 \mathrm{~h}$ after dose administration at $73 \mathrm{nM}$ $\left.(16 \mathrm{~nm} \mathrm{SiO})_{2}\right)$ or $0.5 \mathrm{nM}(85 \mathrm{~nm} \mathrm{SiO}$ ) in water (black), normal (NSCM, blue), or reduced (RSCM, red) serum containing media. DLS size distributions for the NSCM and RSCM alone (dashes) were included as controls to ensure that the target nanoparticles were reliably detected against the light-scattering background of serum molecules.

model (i.e., volume $=$ agglomerate area $\wedge$ scaling factor) to yield a description of each agglomerate's volume (Figure 3a). A scaling factor of 1.33 was empirically defined by comparison of the transformed 2-D area data to measurements taken from a series of 3-D agglomerate reconstructions, obtained by rotating (Figure 3b) cryogenic snapshot sampled agglomerate specimens of a range of sizes within the TEM and acquiring their dimensionality from $\sim 100$ image "tilt series" (full resolution tilt series shown in Video S1/all tilt-series experiments detailed in full in Figure S7). These transformed data were then used to produce agglomerate volume distributions for the 10 and 50 $\mathrm{nM}$ doses of $20 \mathrm{~nm}$ PS across the NSCM and RSCM serum environments (Figure 3c/d). Specific to the $50 \mathrm{nM} / \mathrm{RSCM}$ combination (Figure $3 \mathrm{~d}$ ), this revealed a "tail" of extremely large agglomerates $\left(>10^{8} \mathrm{~nm}^{3}\right)$ that were hidden in the original agglomerate area distributions (Figure 2f) due to a low frequency of occurrence $(<\sim 2 \%)$. As the fluorescence intensity of the PS nanoparticles is proportional to their volume (shown in Figure S8), these agglomerate volume distributions (Figure $3 \mathrm{c} / \mathrm{d}$ ) should (and indeed do) correlate to the delivered cellular dose measurements obtained optically by imaging cytometry (Figure 3e/f). This comparison demonstrates the critical importance of this small subpopulation of very large agglomerates in driving (1) the overall increase in cellular delivery (Figure $1 \mathrm{~b}$ ) and (2) the $>10$-fold cell-to-cell variability in the delivered dose noted specific to the "extreme" agglomeration state formed by the $50 \mathrm{nM}$ dose/RSCM combination (Figure $3 \mathrm{f} / \mathrm{h}$ ).

Impact of Agglomeration State on Nanoparticle Dosimetry. To further understand the extreme agglomeration state formed from the $20 \mathrm{~nm}$ PS/50 nM dose/RSCM combination, the total amount of nanoparticle material (i.e., the product of agglomerate population $\%$ and agglomerate volume) was evaluated for each agglomerate size (Figure 4a). The results highlight a marked serum-related difference in the proportion of the $50 \mathrm{nM}$ administered dose contained within large agglomerates (cross-sectional areas $>10^{5} \mathrm{~nm}^{2}$ ). In turn, the cumulative distribution function of the administered dose, proceeding from the largest to the smallest size-fraction of agglomerates, shows that in RSCM the largest $2 \%$ of agglomerates contained and delivered $90 \%$ of the administered dose, while in NSCM this same $2 \%$ size-fraction contained just $50 \%$ of the administered dose (Figure $4 \mathrm{~b}$ ). This means that the $50 \mathrm{nM}$ administered dose of $20 \mathrm{~nm}$ nanoparticles formed a bioavailable dose of $\sim 2 \mathrm{nM}$ of agglomerates with a mean diameter of $<60 \mathrm{~nm}$ in NSCM. In contrast, a dose of just $\sim 3$ $\mathrm{pM}$ was established from agglomerates with a mean diameter of $>500 \mathrm{~nm}$ in RSCM. Thus, this explains the extensive nanoparticle cell surface binding that occurred when the cells were exposed to the $20 \mathrm{~nm}$ PS/50 nM dose/RSCM combination (Figure $1 \mathrm{~b}$ ), suggesting that the majority of the administered nanoparticle dose was contained in agglomerates too large to be internalized by the cells.

Stress-Testing the DLS Results. While CSS-TEM is a high-resolution technique that is well suited to defining the specifics of nanoparticle agglomeration in biological matrices, its low-throughput, specialist nature limits its applicability for the rapid nanosafety screening of ENMs. We therefore compared the direct, agglomerate size measurements from the CSS-TEM studies to the full DLS size distributions (by number, extracted from results presented in Table 1) to permit a thorough "stress-testing" of the conditions under which the commonly used DLS technique can reliably inform on agglomerate state. For CSS-TEM, Feret diameter measurements were extracted for this comparison ${ }^{42}$ due to the inherent weighting of DLS toward the longest dimension of a scattering 
body (i.e., due to $I_{\mathrm{sc}} \propto d^{6}$, see introduction). Given the wide dynamic range of PS agglomerate sizes known to be established in the NSCM/RSCM environments, size distributions were plotted on double-log axes to facilitate visualization and comparison. Negative, "media control" data for the NSCM/ RSCM media in the absence of nanoparticles were included in all DLS analyses to ensure that the nanoparticles were being reliably detected and/or distinguished against the background light scatter from the serum molecules. For the size distributions recorded in water (the manufacturer's dispersant for all stock nanoparticle solutions) measurements of individual nanoparticle diameters (i.e., primary size distributions) from drop-cast TEM samples were also included to inform on stock colloid stability and to provide a point of reference for the size of individual nanoparticles relative to agglomerates.

Comparison of the primary size, DLS, and CSS-TEM results for the $20 \mathrm{~nm}$ PS in water for both 10 and $50 \mathrm{nM}$ administered doses (Figure $5 \mathrm{a} / \mathrm{b}$, respectively) showed strong agreement in the measurements recorded across all three techniques. This is encouraging, as these conditions (i.e., monodisperse, free from the influence of other scattering particulates) should be where DLS performs optimally. Comparison of the primary size distributions (i.e., individual particle measurements) to the agglomerate size distributions (i.e., measured by DLS or CSSTEM) also confirmed the colloidal stability of these aqueous solutions, showing that less than $\sim 10 \%$ of particulate sizefractions occupied sizes greater than the maximum primary particle size. In NSCM at $10 \mathrm{nM}$ concentration (Figure 5c), the $20 \mathrm{~nm}$ PS were undetectable against the serum protein background by DLS, as shown by the size distribution's direct overlay with the NSCM media control and by comparison to the true size distribution defined by CSS-TEM. When the nanoparticle dose was increased 5 -fold to $50 \mathrm{nM}$ however (Figure 5d), both serum proteins (first peak from left, identifiable against the NSCM control) and the target nanoparticles (second peak, aligned with CSS-TEM) were detectable by DLS in the NSCM environment. Similarly, when the serum concentration was reduced to $2 \%$ (i.e., RSCM), the $10 \mathrm{nM}$ nanoparticle dose (Figure 5e) was detectable against the RSCM background. Finally, the abrupt change to an extreme state of agglomeration- noted specific to the $20 \mathrm{~nm}$ PS/50 nM dose/RSCM combination-was detectable by DLS (Figure 5f), but the abundance of large agglomerates can be seen to be overestimated by comparison to the CSS-TEM distribution. Contrastingly, comparison of the $40 \mathrm{~nm}$ PS results (Figure $5 \mathrm{~g}$ / h) obtained across measurement techniques in water, NSCM, or RSCM dispersants showed little evidence of any changes in agglomeration state from that of the stock, aqueous solution.

Employing Lessons Learned in DLS Interpretation: $\mathrm{SiO}_{2}$ Nanoparticles. To test the lessons learned in DLS interpretation-aided by growth medium and primary size controls-Figure 6 presents agglomeration state characterizations for the 16 and $85 \mathrm{~nm} \mathrm{SiO}_{2}$ nanoparticles where corresponding CSS-TEM analyses were not made. In water, excellent alignment between the primary size distributions and the DLS results was observed for both nanoparticle sizes (Figure 6a/b). Comparison of the $16 \mathrm{~nm} \mathrm{SiO}_{2}$ DLS data across the NSCM and RSCM serum environments (Figure 6c) showed very different agglomeration states formed, with much larger agglomerates identified in RSCM. Here, the distribution in NSCM also presented two distinct peaks, the first (from left) of which can be attributed to serum particulate scatter by comparison against the NSCM media control and because it falls below the known lower limit of the particles' primary size $(\sim 10 \mathrm{~nm})$ (Figure 6a). Similarly, whereas the $85 \mathrm{~nm} \mathrm{SiO}$ agglomerate size distributions by DLS (Figure 6d) were quite similar across serum environments, the distribution in RSCM shows two distinct peaks. Again, comparison of this first peak to the primary size distribution (Figure $6 \mathrm{~b}$ ) shows it falls below the lower limit of the nanoparticles' primary size $(\sim 40 \mathrm{~nm})$ and thus cannot represent the target nanoparticles.

Consequences of Serum-Dependent $\mathrm{SiO}_{2}$ Agglomeration: Cell Viability and Cellular Delivery. Following up on the $\mathrm{SiO}_{2}$ agglomeration state characterizations in each serum environment (Figure 6), the potential for any concomitant, serum-dependent differences on cellular toxicity arising upon exposure to the $\mathrm{SiO}_{2}$ nanoparticles was investigated. Using test methods previously optimized in-house for nanoparticle test materials, ${ }^{21,38}$ TK6 cell viability after $24 \mathrm{~h}$ exposure was assessed by relative population doubling analysis. Alongside in duplicated, satellite cell cultures, the potential for chromosomal damage was also assessed using the binucleated cell micronucleus assay (alternative mass/volume and surface area dose metrics provided in Table S2). When considering the $16 \mathrm{~nm}$ $\mathrm{SiO}_{2}$ results, it was immediately apparent that administered doses of $>15 \mathrm{nM}$ had a heightened effect on cell viability when administered in RSCM compared to in NSCM (Figure 7a). Employment of quantitative dose-response modeling (i.e., "benchmark dose" nonlinear regression analysis) indicated that, as a result of this serum-dependent effect, the dose of $16 \mathrm{~nm}$ $\mathrm{SiO}_{2}$ required to cause a $50 \%$ decrease in cell viability was approximately 2.5 times less in the RSCM environment compared to that in NSCM (analysis presented in Figure S9a). In contrast, administered doses of the $85 \mathrm{~nm} \mathrm{SiO}_{2}$ caused similar dose-dependent decreases in cell viability regardless of NSCM or RSCM serum environment (Figure 7b). This observation was also supported by the dose-response modeling, which rejected serum environment as an influential covariate, showing that all $85 \mathrm{~nm} \mathrm{SiO}_{2}$ cell viability data, regardless of serum environment, were well-described by a single dose-response model (analysis presented in Figure $\mathrm{S} 9 \mathrm{~b})$. In keeping with previous findings, ${ }^{33}$ micronucleus test results showed that both the $16 \mathrm{~nm} \mathrm{SiO}_{2}$ and the $85 \mathrm{~nm} \mathrm{SiO}$ were weakly genotoxic, with exposures to the $50 \%$ cytotoxicity cutoff causing maximum micronucleus inductions of around 2.5-fold (bars; Figure 7a/b).

To unravel the serum-dependent effects underlying the cell viability studies, the cellular delivery of the $\mathrm{SiO}_{2}$ nanoparticles was investigated by sectioned-cell TEM, with supporting EDX analyses used to unequivocally identify the delivered dose of nanoparticles (false-colored green; Figure 8; a further $\sim 20$ images for each dose and serum environment alongside EDX spectra are also presented in Figures S10-S13). Similar to the $20 \mathrm{~nm}$ PS findings at $50 \mathrm{nM}$, the results highlighted a dramatic increase in the quantity of $16 \mathrm{~nm} \mathrm{SiO}_{2}$ nanoparticles found bound to cell membranes in RSCM compared to NSCM (Figure $8 \mathrm{a} / \mathrm{b}$ ). In contrast, the delivered cellular doses of $85 \mathrm{~nm}$ $\mathrm{SiO}_{2}$ remained similar regardless of serum environment (Figure $8 \mathrm{c} / \mathrm{d}$ ). Taken in combination, it is thus again evident that serum-dependent differences in the agglomeration state of the $16 \mathrm{~nm} \mathrm{SiO} 2$ - successfully detected here by DLS alone (Figure 6c) - underpin the differences in cellular delivery (Figure $8 \mathrm{a} / \mathrm{b}$ ) and subsequent toxicity (Figure $7 \mathrm{a}$ ) observed specific to administered doses of $16 \mathrm{~nm} \mathrm{SiO} 2$ above $15 \mathrm{nM}$.

Dependency of Agglomeration State on Dose and Serum Availability. The central tenet of toxicity testing is that 

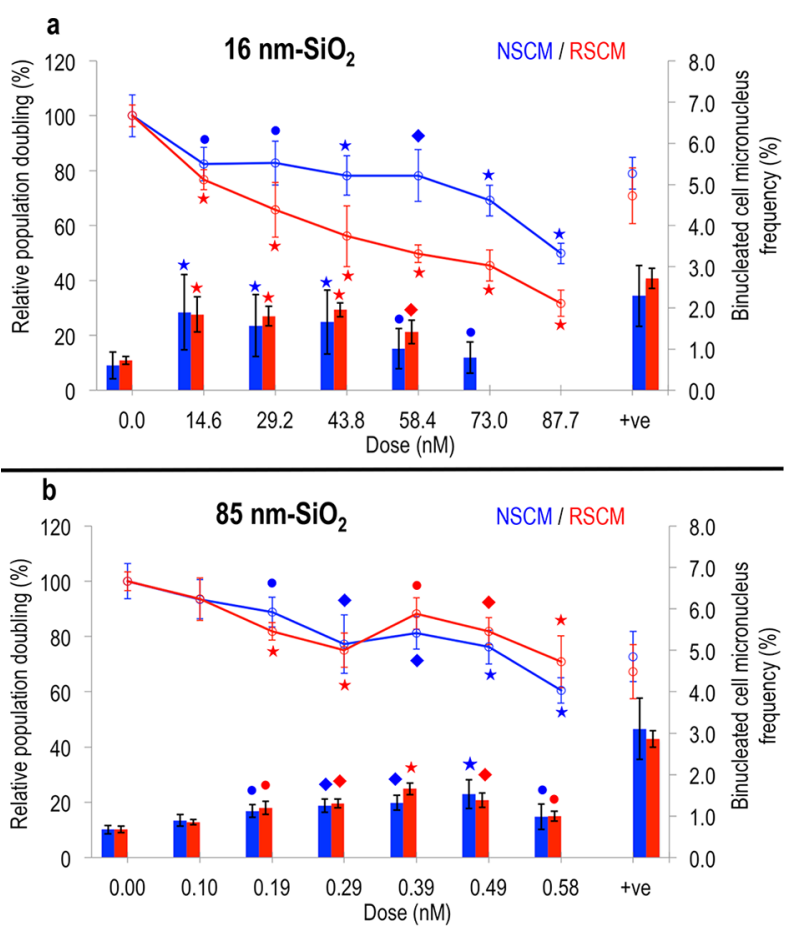

Figure 7. Impact of the $\mathrm{SiO}_{2}$ nanoparticles on cell viability and DNA damage in normal or reduced serum containing media. TK6 cells were exposed $(24 \mathrm{~h})$ to doses of $(\mathrm{a}) 16 \mathrm{~nm} \mathrm{SiO}$ or $(\mathrm{b}) 85 \mathrm{~nm}$ $\mathrm{SiO}_{2}$ in normal (NSCM, blue) or reduced (RSCM, red) serum containing growth medium $(n=6$, error bars $=$ SD $)$. The impact of exposure on cell viability (cell growth/cytotoxicity) was assessed in terms of relative population doubling (lines) relative to unexposed control cultures. DNA damage (bars) was assessed via binucleated cell micronucleus frequency until cell viability decreased below $50 \% .(\bullet, \star)$ Response statistical significance relative to undosed control at $p<0.05, p<0.01$, and $p<0.001$, respectively. (a) At administered doses of $>15 \mathrm{nM}$, the $16 \mathrm{~nm} \mathrm{SiO}$, showed distinctly different trends in cell viability across serum environments. (b) In contrast, cell viability data for the $85 \mathrm{~nm} \mathrm{SiO}{ }_{2}$ exposures remained highly similar regardless of serum environment.

the quantified biological response indicates the potency of the toxin at the administered dose (i.e., "the dose makes the poison"). However, since the particokinetics of nanoparticle dispersions are time and environment dependent, the administered form of the material is not necessarily the same as that encountered by the target cell. ${ }^{3,13,43}$ Consequently, dose-response profiling has the potential to become misleading as the measured response becomes a reaction to an inaccurately quantified dose. ${ }^{43,44}$ Here, the $20 \mathrm{~nm}$ PS and 16 $\mathrm{nm} \mathrm{SiO}_{2}$ results provide a vivid example of the difficulties that can arise. When considering the relationship between the administered and delivered doses for typical concentrations of test materials $(0-73 \mathrm{nM})$, abrupt "tipping points" emerged at which the administered nanoparticle dose suddenly changed agglomeration state, showing a dynamic interplay between the surface area of the dose and the availability of serum. ${ }^{10}$ These findings suggest that excess serum can promote nanoparticle dispersity, perhaps because a surface coating of serum facilitates steric hindrance between nanoparticles, inhibiting their collision to form agglomerates. ${ }^{45,46}$ In this scenario, excess serum plays a surface-passivating role, ${ }^{10}$ stabilizing the nanoparticle dispersion and preventing agglomeration until, with increasing dose or decreasing serum concentration, serum abundance becomes limited, triggering a tipping point change in agglomeration state.

Whereas the results thus indicate a general link between the administered dose, the availability of serum, and the onset of changing agglomeration states, closer scrutiny shows that a simple, predictable relationship between the total surface area of an administered dose and the onset of tipping point changes in agglomeration did not occur. More specifically, it is observed that exposures to the $40 \mathrm{~nm}$ PS and $85 \mathrm{~nm} \mathrm{SiO}_{2}$ nanoparticles failed to elicit a tipping point, despite the utilization of administered doses with equal or greater total surface areas to those that caused the effect with the smaller, yet otherwise compositionally identical $20 \mathrm{~nm}$ PS or $16 \mathrm{~nm} \mathrm{SiO} 2$ (shown diagrammatically in Figure S14). It is suggested that this disparity likely reflects the complexity of factors underpinning these tipping points, resulting in a tendency for them to be challenging to predict from a theoretical basis. For example, the failure of the larger nanoparticle size-types (i.e., the $40 \mathrm{~nm}$ PS and $85 \mathrm{~nm} \mathrm{SiO}$ ) to elicit a tipping point may further indicate the importance of size-specific diffusion speeds and therefore particle-particle collision energies in agglomerate formation. ${ }^{47,48}$ With specific regard to the absence of a tipping point during the $40 \mathrm{~nm}$ PS exposures, it is observed that even at doses with equivalent surface areas to those where $20 \mathrm{~nm}$ PS doses elicited the effect, the fact that the two particle types possess different densities of surface carboxyl groups (see Methods) will confer different abilities to bind serum and trigger the tipping point.

The data therefore indicate that the inherent unpredictability of these tipping points necessitates the robust, empirical techniques presented here to permit successful detection. This is because any sudden onset in nanoparticle agglomeration has the effect that the test material changes abruptly midassay from a nano- to a microparticulate. This not only decouples the administered dose from that delivered to the cells ${ }^{49}$ but also dramatically alters nanoparticle-cell interactions such that the quantity, cell-to-cell variability, and localization (e.g., cellmembrane-bound versus internalized) of the delivered dose all abruptly change. Successful detection of these tipping points is therefore essential, as, once triggered, these changes invalidate the standard dose-response framework from both directions as the dose is inaccurately quantified and the nature of the exposure driving the biological response changes midassay.

\section{CONCLUSIONS}

Understanding the transformation of nanoparticle dose under relevant physiological and/or experimental conditions is essential for the efficacy of nanomedicines, as well as for all in vitro, in vivo, and ecological testing strategies if nanosafety evaluations are to become more reliable, realistic, and predictive. ${ }^{13-15}$ The results herein show study design reconsiderations for nanoparticle testing are required in vitro as we challenge the usual assumptions that (1) agglomeration state characterization for a single dose adequately represents all exposures in an employed dose range; ${ }^{22-26}(2)$ administered dose can be used to compare toxicity results across cell lines, growth media, ${ }^{22,25}$ and serum combinations ${ }^{23,24}$ without full consideration of the impact these different environments have on cellular delivery; and (3) it is sufficient to define adverse response as an average from a treated cell population without consideration of cell-to-cell variability in dose delivery. ${ }^{50-52}$

We assert that strategies do exist to tackle these challenges. If the traditional paradigm of measuring averaged cell population 

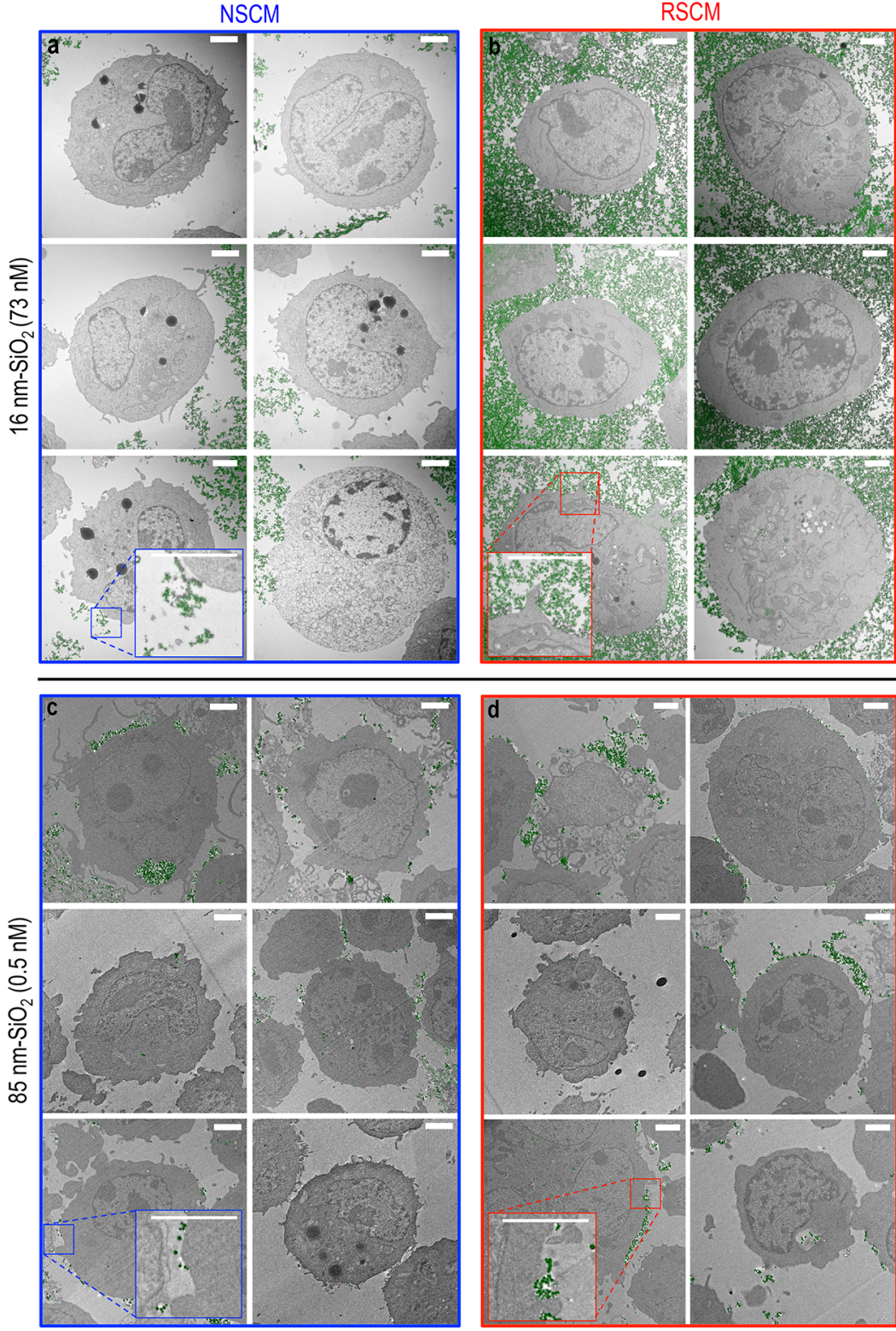

Figure 8. Cellular delivery of the $\mathrm{SiO}_{2}$ nanoparticles in normal or reduced serum containing media. To understand the cellular delivery of the $\mathrm{SiO}_{2}$ nanoparticles in normal (NSCM, blue) and reduced (RSCM, red) serum environments, electron microscopy of sectioned cells was carried out $24 \mathrm{~h}$ after exposure, with energy dispersive X-ray (EDX) analysis used to identify the nanoparticles (false-colored green). (a/b) Cellular delivery of the $16 \mathrm{~nm} \mathrm{SiO} \mathrm{S}_{2}(73 \mathrm{nM}$ dose) varied dramatically across serum environments, with much greater quantities of nanoparticles observed bound to cell membranes in RSCM (b) when compared to NSCM (a). In contrast (c versus d), cellular delivery of the $85 \mathrm{~nm} \mathrm{SiO} 2(0.5 \mathrm{nM}$ dose $)$ remained highly similar regardless of serum environment. Scale bars $=1 \mu \mathrm{m}$.

responses is to be maintained, it is clear that quantification of the bioavailable dose for the full set of experimental exposures will be required. To this end, we demonstrate the reliability of the popular, high-throughput DLS approach can be significantly improved if the user examines log-scaled number distributions and includes primary size and growth medium controls. Our findings show that while DLS is inaccurate for the absolute quantification of agglomeration state, it can identify tipping points in agglomeration state and the concomitant illegitimacy of a nanosafety dose-response profile. Where DLS fails (e.g., small nanoparticles/low concentrations of test-material/high environmental biomolecule concentrations) or where detailed specifics of agglomeration dynamics are required (e.g., to better understand the dosimetry of nanomedicines) we further demonstrate the 3-D CSS-TEM approach. Although this is ultimately lower-throughput and requires specialized equipment, we show it is extremely well-suited to provide highresolution insights into the precise nature of nanoparticle agglomeration under conditions where current techniques fail.

An alternative and previously advocated approach to addressing the issues raised here involves the employment of dispersion strategies to create monodisperse nanoparticle suspensions in vitro. ${ }^{6,12,53,54}$ Such approaches have been shown to dramatically improve the reproducibility of in vitro nanosafety results ${ }^{6}$ and also to permit the accurate computational modeling of nanoparticle cellular delivery. ${ }^{6,53-55}$ It is also thought that the latest generation of these dosimetry models offer the potential to accurately predict the delivery of polydisperse nanoparticle dispersions, if equipped with accurate, empirical descriptions of agglomeration state. ${ }^{54}$ For 
this purpose, it is suggested that the 3-D CSS-TEM approach presented here is well-suited to provide the required data, thus enabling the further development and stress-testing of these essential exposure characterization tools.

Ultimately, the data presented in this report demonstrate that such progress toward fully understanding the cellular delivery of polydisperse nanoparticle exposures is essential. This is because outside of the in vitro domain it remains that real-world human, environmental, and medical nanoparticle exposures are unlikely to be monodisperse and hence will be cellularly presented as the complex and dynamic agglomerated size ranges discussed herein. We therefore demonstrate precise quantification, definition, and comparison of the bioavailable dose established by complex agglomeration processes and show that this description is critical to understanding cellular delivery, uptake, and toxicity. Importantly, our approaches are broadly applicable to other biological matrices where existing technologies and current understanding of test-material and nanomedicine dosimetry fail.

\section{METHODS/EXPERIMENTAL}

Primary Nanoparticle Physicochemical Characterization. Nanoparticle samples were prepared for primary size (i.e., individual particle) characterization by drop-casting aqueous solutions onto glowdischarge-treated standard holey carbon TEM support grids (Agar Scientific, Stansted, UK) at the concentrations indicated in the text. TEM in conjunction with EDX spectroscopy was used to determine size, shape/morphology, crystallinity, composition, and purity. Nanoparticle primary size distributions were constructed from individual nanoparticle diameter measurements $(n>120)$ made from bright-field electron micrographs using the Image software. $^{56}$

Cell Preparation and Nanoparticle Exposures. TK6 human B lymphoblastoid cells (\#95111735, Health Protection Agency) were maintained in RPMI 1640 medium (\#32404014, ThermoFisher) supplemented with $1 \mathrm{mM}$ glutamine and either normal (10\%) (NSCM) or reduced (2\%) (RSCM) horse serum (\#16050122, ThermoFisher). Cell cultures were maintained in an atmosphere of $5 \% \mathrm{CO}_{2}$ in humidified air at $37{ }^{\circ} \mathrm{C}$. Prior to nanoparticle exposure, independent cell populations were established at $2 \times 10^{5}$ cells $/ \mathrm{mL}$ in T25 culture flasks. Exposures to the $20 \mathrm{~nm}$ PS or $40 \mathrm{~nm}$ PS nanoparticles were to 20 or $40 \mathrm{~nm}$ carboxylate surface-modified (surface charge densities $=0.7152$ and $3.0420 \mathrm{mEq} / \mathrm{g}$, respectively), yellow-green fluorescent (excitation/emission $=505 / 515 \mathrm{~nm}$ ), neutrally buoyant $\left(\right.$ density $=1.05 \mathrm{~g} / \mathrm{cm}^{3}$ ) FluoSphere polystyrene latex nanoparticles (\#F8787 and \#F8795, ThermoFisher). Exposures to the $16 \mathrm{~nm} \mathrm{SiO}$ or $85 \mathrm{~nm} \mathrm{SiO}$ were to 16 or $85 \mathrm{~nm}$ amorphous silicon dioxide $\left(\mathrm{SiO}_{2}\right)\left(\right.$ density $\left.=2.65 \mathrm{~g} / \mathrm{cm}^{3}\right)$ nanoparticles (Levasil 200 or Levasil 50, BASF). Flasks were returned to the incubator for the $24 \mathrm{~h}$ exposure period. Further mixing during exposure was not employed in an effort to (a) replicate the typical exposure approach commonly used by the majority of in vitro nanosafety studies and (b) to ensure cell division-critical to the success of the micronucleus assay-was not inadvertently disrupted. Dose was increased until either a 50\% reduction in cell viability was reached (i.e., according to OECD test guideline 487$)^{31}$ or until the maximum dose permitted by the stock nanoparticle solution's concentration was reached. Immediately after exposure, cells were transferred to $15 \mathrm{~mL}$ conical tubes (\#430791 Sigma), pelleted by centrifugation (10 min; 129g), and the nanoparticle-containing supernatant was fully aspirated by pipet. The cell pellet was then resuspended by flicking the tube prior to repeating this process twice via two further wash steps each using 12 $\mathrm{mL}$ of prewarmed phosphate-buffered saline (PBS) $\left(37^{\circ} \mathrm{C}\right)$. After washing, cells were immediately prepared for characterization of cellular delivery by either imaging flow cytometry or sectioned-cell TEM.

Imaging Flow Cytometry. Cells were resuspended in PBS at $1 \times$ $10^{7}$ cells $/ \mathrm{mL}$ concentration prior to image collection using an IS100 imaging flow cytometer (Amnis Corporation). A $405 \mathrm{~nm}$ wavelength laser was used to excite PS nanoparticle fluorescence, which was collected in the 505-560 $\mathrm{nm}$ spectral detection range. A sample of 10000 cell images was taken from each cell population $(n=4)$ and analyzed using the manufacturer's IDEAS software. Two-dimensional plots of cell area and aspect ratio were used to isolate single, viable cells with this population further refined to cells within the focal plane by linescan gradient. This process reduced the analyzed cell populations to $\sim 5000$ cells; hence $\sim 2 \times 10^{4}$ cells total were assessed per dose across the four independent experimental replicates. The delivered nanoparticle dose per cell was measured as the integrated fluorescence intensity within the bright-field delineated area of each cell.

Confocal Microscopy. Microscopy coverslips were preincubated in poly-L-lysine $(1 \mathrm{mg} / \mathrm{mL})$ to facilitate attachment of fixed $(4 \%$ paraformaldehyde), pre-exposed cells. A $5 \mu \mathrm{g} / \mathrm{mL}$ concentration of Alexa Fluor 633 conjugated wheat germ agglutinin (W21404, ThermoFisher) in 1\% Hank's balanced salt solution (HBSS)-buffered bovine serum albumin was used to label cell membranes (15 min incubation). To label the cytoskeleton, cell-loaded coverslips were first permeabilised with $0.1 \%$ Triton X-100 ( $3 \mathrm{~min}$ ) prior to $15 \mathrm{~min}$ of incubation with $33 \mathrm{nM}$ HBSS-buffered Alexa Fluor 594 conjugated phalloidin (A12381, ThermoFisher). Coverslips were then washed three times in fresh HBSS and mounted on slides in glycerol-based mounting medium with or without Hoechst 33342 nuclear stain (1 $\mu \mathrm{g} / \mathrm{mL}$ ). Images were recorded as 2-D optical sections and as 3-D reconstructable "Z-stacks" using an LSM-710 confocal microscope equipped with a $40 \times / 1.3 \mathrm{NA}$ oil immersion objective (Carl-Zeiss).

PS Nanoparticle Fluorescence Properties and pH Stability. To determine if fluorescence was a function of nanoparticle volume, the photon luminescence of the compositionally identical $40 \mathrm{~nm}$ PS and $20 \mathrm{~nm}$ PS was compared at equal number concentrations (i.e., 20 $\mathrm{nM}$, aqueous solutions), confirming the expected 8-fold volume-based relationship. Fluorescence stability was further assessed in water (manufacturer's dispersant), NSCM, and RSCM, as well as in three previously described ${ }^{57}$ incubation buffers designed to mimic the different $\mathrm{pH}$ stages of the endosomal-lysosomal life cycle: the $\mathrm{pH} 7.0$ buffer was phenol red free RPMI 1640 (\#32404014, ThermoFisher), while the $\mathrm{pH} 5.5$ and $\mathrm{pH} 4.5$ buffers were combinations of $0.1 \mathrm{~N}$ sodium acetate and $0.1 \mathrm{~N}$ acetic acid $\left(\mathrm{p} K_{\mathrm{A}}\right.$ 4.76). Nanoparticle fluorescence was quantified using a QuantaMaster spectrofluorimeter (Photon Technology International) as the integrated photon luminescence across the spectral detection range $(505-560 \mathrm{~nm})$ used in the cell-delivery study by imaging cytometry.

Agglomerate Analysis. PS nanoparticles were added to T25 culture flasks containing NSCM or RSCM but absent of cells. Flasks were returned to the incubator for $1 \mathrm{~h}$ to allow agglomeration processes to occur prior to characterization by CSS-TEM or DLS. Continuous carbon films supported by copper TEM grids (\#AGS1604, Agar Scientific) were glow discharged at $5 \mathrm{kV}$ for $30 \mathrm{~s}$ before loading with $3.5 \mu \mathrm{L}$ droplets of the nanoparticle-media suspension inside the preparation chamber of the Mark IV Vitrobot (FEI), which was maintained under cell culture conditions at $37^{\circ} \mathrm{C}$ and $95 \%$ humidity. A $30 \mathrm{~s}$ delay was applied to ensure the droplet was equilibrated before blotting and vitrification through rapid plunge freezing into liquid ethane. Prepared grids were transferred into a vacuum desiccator and then allowed to warm to room temperature, thereby preserving particle agglomeration states. ${ }^{20}$ Samples were then imaged by brightfield TEM (150 micrographs yielding 1300-5000 agglomerates per dose/serum sample). Agglomerates were manually segmented to binary masks and automatically measured using ImageJ (detailed methodology presented, Figure S6). Five $\sim 100$-image tilt-series sequences of CSS sampled agglomerates with sizes spanning the range measured in the zero-tilt CSS-TEM study (i.e., one agglomerate per each size fraction on the order of $0.1,1,2,3$, and $4 \mu \mathrm{m}$ in diameter) were collected to assess 3-D morphology (presented in Figure S7/Video S1). Bright-field TEM images were collected at 1 degree intervals over the largest accessible tilt range for each individual agglomerate. The data were reconstructed using the Tomo ${ }^{58}$ plugin for ImageJ. All five tilt series show the agglomerates to be flattened, 
presumably due to the blotting step in the CSS preparation for TEM. Normalized agglomerate volumes were thus obtained by multiplying the imaged agglomerate area (normalized to the area of the smallest agglomerate) by its thickness estimated from the tilt-series reconstruction (and normalized to the thickness of the smallest agglomerate), i.e., assuming the agglomerates were all plate-like.

Dynamic Light Scattering. The dynamic viscosity of RSCM and NSCM at $37^{\circ} \mathrm{C}$ was determined as 0.7223 and $0.7572 \mathrm{cP}$, respectively, by the U-tube viscometer method, ${ }^{59}$ with both possessing a measured refractive index of $\sim 1.34$. To obtain informative size data, care was taken to reproduce the exact process used to expose cells; thus dispersions were prepared in T25 culture flasks and returned to the incubator for $1 \mathrm{~h}$ to allow agglomeration processes to occur. A $500 \mu \mathrm{L}$ amount of each nanoparticle dispersion at the concentrations stated in the text were then loaded into capillary cells (\#DTS1061, Malvern) and analyzed with a ZetaSizer Nano ZS instrument (Malvern). Samples were allowed to equilibrate at $37{ }^{\circ} \mathrm{C}$ for $2 \mathrm{~min}$ prior to size (hydrodynamic diameter) and surface charge (zeta potential) measurement. Size measurements were calculated from the average of ten $100 \mathrm{~s} \mathrm{scans}$; charge measurements, from the average of ten $10 \mathrm{~s}$ scans, with all DLS analyses repeated in duplicate from independently prepared dispersions. Media controls (i.e., dispersants without nanoparticles) were also included in all size analyses to ensure nanoparticles were reliably detected against the serum protein background. The dielectric constant of NSCM/RSCM was assumed to be 74.5 , and Henry's function was set at the Smoluchowski approximation of $F(\kappa a)=1.5$. Number distributions by population percentage were exported using the ZetaSizer software (v6.20, Malvern).

Cell Viability and DNA Damage Studies. Cell viability and chromosomal damage resultant from the $24 \mathrm{~h}$ nanoparticle exposures were assessed by relative population doubling (RPD) analysis and the cytokinesis blocked micronucleus assay using duplicated, satellite cultures. On day 1 , cultures were established at $\sim 2 \times 10^{5}$ cells $/ \mathrm{mL}$ (count 1) prior to nanoparticle exposure for $24 \mathrm{~h}$, washing twice with $\mathrm{PBS}$, and leaving to recover for one cell cycle (17 h) (count 2), with 3 $\mu \mathrm{g} / \mathrm{mL}$ cytochalasin $\mathrm{B}$ included in cultures for the micronucleus assay. $\mathrm{RPD}$ (\%) was calculated as (no. population doublings (PD) in treated cultures/no. PDs in control cultures) $\times 100$, where PD was defined as $(\log 10(\operatorname{count} 2 / \operatorname{count} 1)) / \log (2)$. Mitomycin $C$ at $0.01 \mu \mathrm{g} / \mathrm{mL}$ (\#M7949, Sigma) was used as a positive control. Cells were prepared for micronucleus analysis by resuspension in $0.56 \%$ potassium chloride hypotonic solution, followed by $10 \mathrm{~min}$ of incubation in "fixative one" (5:1:6 methanol-acetic acid- $0.9 \%$ sodium chloride) at $4{ }^{\circ} \mathrm{C}$. Cells then underwent four 10 min changes of "fixative two" (5:1 methanolacetic acid; $4{ }^{\circ} \mathrm{C}$ ) and were left in the final wash overnight. The resultant fixative/cell suspension was pipetted onto polished slides, which were allowed to air-dry prior to nuclear staining with $0.15 \mu \mathrm{g} /$ $\mathrm{mL}$ 4',6-diamido-2-phenylindole (DAPI). The presence of micronuclei in binucleated cells (three replicates, 2000 cells scored per replicate) was assessed automatically using an Axioimager Z2 fluorescent microscope (Carl-Zeiss) equipped with an automated stage using the Metafer 4 software (MetaSystems). Micronucleated cells were manually validated using the $100 \times$ objective.

Preparation of Sectioned Cells for Transmission Electron Microscopy. All buffers in the following steps were $200 \mathrm{mM}$ and maintained $\mathrm{pH} 7.3$. After $24 \mathrm{~h}$ of exposure to the 16 or $85 \mathrm{~nm} \mathrm{SiO}$, the TK6 cells were washed twice with PBS and fixed in 2.5\% Millonig's buffered glutaraldehyde for $4 \mathrm{~h}$ at $4{ }^{\circ} \mathrm{C}$ (\#R1314, Agar Scientific). Cells were then postfixed in $1 \%$ phosphate-buffered osmium tetroxide for 2 $\mathrm{h}$ in the dark at $4{ }^{\circ} \mathrm{C}$ prior to dehydration through an aqueous ethanol series $(25 \%, 70 \%, 90 \%,(100 \% \times 2))$; then, two changes of $100 \%$ propylene oxide were performed. Resin infiltration involved $90 \mathrm{~min}$ of incubation in 1:1 medium resin (\#T028, TAAB) to propylene oxide, followed by overnight incubation in $100 \%$ resin at $4{ }^{\circ} \mathrm{C}$, prior to baking for $24 \mathrm{~h}$ in fresh resin. Embedded samples were sectioned on an EM-UC7 ultramicrotome (Leica) using a $45^{\circ}$ diamond knife (Diatome) with sections picked up on 150 mesh copper grids (\#G2150C, Agar Scientific) and sputter coated with $\sim 10 \mathrm{~nm}$ of carbon to enhance electron conductivity.
Transmission Electron Microscopy/X-ray Microanalysis. TEM was carried out at $200 \mathrm{kV}$ using a Tecnai F20 field emission gun TEM (FEI) fitted with a high-angle annular dark field detector (Fischione) and an INCA 350 EDX spectrometry system using an 80 $\mathrm{mm}^{2}$ silicon drift detector (Oxford Instruments). Images were recorded using an Orius SC600A CCD camera (Gatan).

Statistical Analyses of Dose-Response Data. Response significance relative to untreated control was assessed by pairwise testing according to the framework laid out by Johnson et al. ${ }^{60}$ Briefly, response data were assessed for homogeneity of variance and distribution normality by Bartlett and Shapiro-Wilk tests, respectively, after $\log _{10}$ transformation. If the transformed data passed these tests $(p$ $>0.05)$, comparisons to negative controls employed one-sided ( $\mathrm{MN})$ or two-sided (cell viability) post hoc Dunnett's tests with alpha set at 0.05 . Data sets that failed either test $(p<0.05)$ were analyzed using the nonparametric post hoc Dunn's test. Statistical analyses were conducted using the online tool DRSMOOTH via Swansea University's Mutation Analysis Informatic Tools Web site (MutAIT.org). ${ }^{61}$ Benchmark dose (BMD) (i.e., nonlinear regression analysis) was carried out using the combined $\mathrm{BMD}$-covariate method described extensively in previous work. $^{62,63}$ Briefly, analyses were carried out using the freely available PROAST package (http://www.proast.nl) in the $\mathrm{R}$ computing environment. Dose-response data were analyzed using a nested family of four-parameter exponential models recommended by the European Food Safety Authority for the analysis of continuous toxicity data. ${ }^{64,65}$ In each analysis, combined data sets (i.e., collected across NSCM/RSCM serum environments) were analyzed using the factor discriminating the subgroupings (i.e., serum environment) as a covariate. Models were fitted iteratively with more complex models with greater numbers of covariate-dependent parameters only accepted if the difference in log-likelihood exceeded $p<0.05$. In this way, it was established which model parameters needed to be estimated for each subgroup and which parameters could be considered as constants across the subgroups of each combined data set. ${ }^{66}$ Interpolation from the fitted BMD model permitted estimation of the dose (i.e., the BMD) that can be expected to elicit the benchmark response (here, set at a $50 \%$ decrease in cell viability). For the $16 \mathrm{~nm} \mathrm{SiO}$ data set, comparison of the dose-response established in RSCM to that established in NSCM further allowed calculation of a relative potency factor. ${ }^{67}$ This value describes the relative potency of administered doses of the $16 \mathrm{~nm} \mathrm{SiO}_{2}$ in the $\mathrm{RSCM}$ environment relative to that in NSCM (full analysis presented in Figure S9).

\section{ASSOCIATED CONTENT}

\section{S Supporting Information}

The Supporting Information is available free of charge on the ACS Publications website at DOI: 10.1021/acsnano.7b03708.

Full physicochemical characterization data, alongside further confocal microscopy and sectioned-cell delivered dose images; nanoparticle fluorescence stability information; cell viability results; 3-D agglomerate reconstruction information; further statistical/experimental methods and alternative dose metrics (PDF) 3-D agglomerate reconstruction video (AVI)

\section{AUTHOR INFORMATION}

\section{Corresponding Author}

*Tel: +441792 602915. E-mail: h.d.summers@swan.ac.uk. ORCID ${ }^{\circ}$

John W. Wills: 0000-0002-4347-5394

\section{Author Contributions}

J.W.W., H.D.S., A.P.B., and S.H.D. designed the experiments. J.W.W., H.D.S., and P.R. analyzed the data. J.W.W. carried out cell culture, nanoparticle exposures, (geno)toxicity assays, imaging cytometry, DLS, and confocal microscopy. J.W.W., K.E.M., and A.S. conducted the spectrofluorimetry studies. 
J.W.W., A.P.B., and N.H. carried out the CSS-TEM agglomerate analyses and electron microscopy of sectioned cells. P.A.W. provided critical input on the manuscript. J.W.W. and H.D.S. wrote the manuscript in close collaboration with all coauthors. All authors reviewed, contributed in full, and approved the final version of the manuscript.

\section{Funding}

This work was supported by Engineering and Physical Sciences Research Council (EPSRC) grant numbers EP/H008683/1 and $\mathrm{EP} / \mathrm{E} 059678 / 1$.

\section{Notes}

The authors declare no competing financial interest.

\section{ACKNOWLEDGMENTS}

The authors would like to acknowledge the Engineering and Physical Sciences Research Council (EPSRC) for funding this research and for providing J.W.W. with a "Building Global Engagements in Research" bursary, which supported the nanoparticle photonics studies at Texas A\&M University. J.W.W. would also like to thank P. Williams for his input on the DLS data collection and J. Powell for his critical insights.

\section{REFERENCES}

(1) Ferrari, M. Cancer Nanotechnology: Opportunities and Challenges. Nat. Rev. Cancer 2005, 5, 161-171.

(2) Ferrari, M. Nanogeometry: Beyond Drug Delivery. Nat. Nanotechnol. 2008, 3, 131-132.

(3) Lynch, I.; Salvati, A.; Dawson, K. A. Protein-Nanoparticle Interactions: What Does the Cell See? Nat. Nanotechnol. 2009, 4, 546-547.

(4) Monopoli, M. P.; Walczyk, D.; Campbell, A.; Elia, G.; Lynch, I.; Baldelli Bombelli, F.; Dawson, K. A. Physical-Chemical Aspects of Protein Corona: Relevance to In Vitro and In Vivo Biological Impacts of Nanoparticles. J. Am. Chem. Soc. 2011, 133, 2525-2534.

(5) Walczyk, D.; Bombelli, F. B.; Monopoli, M. P.; Lynch, I.; Dawson, K. A. What the Cell "Sees" in Bionanoscience. J. Am. Chem. Soc. 2010, 132, 5761-5768.

(6) Cohen, J.; Deloid, G.; Pyrgiotakis, G.; Demokritou, P. Interactions of Engineered Nanomaterials in Physiological Media and Implications for In Vitro Dosimetry. Nanotoxicology 2013, 7, 41731.

(7) Desai, N. Challenges in Development of Nanoparticle-Based Therapeutics. AAPS J. 2012, 14, 282-295.

(8) Burden, N.; Aschberger, K.; Chaudhry, Q.; Clift, M. J. D.; Doak, S. H.; Fowler, P.; Johnston, H.; Landsiedel, R.; Rowland, J.; Stone, V. The 3Rs as a Framework to Support a 21st Century Approach for Nanosafety Assessment. Nano Today 2017, 12, 10-13.

(9) Tantra, R.; Shard, A. We Need Answers. Nat. Nanotechnol. 2013, $8,71-71$.

(10) Join the Dialogue. Nat. Nanotechnol. 2012, 7, 545-545.10.1038/ nnano.2012.150

(11) Alkilany, A. M.; Mahmoud, N. N.; Hashemi, F.; Hajipour, M. J.; Farvadi, F.; Mahmoudi, M. Misinterpretation in Nanotoxicology: A Personal Perspective. Chem. Res. Toxicol. 2016, 29, 943-948.

(12) Baalousha, M.; Lead, J. R. Nanoparticle Dispersity in Toxicology. Nat. Nanotechnol. 2013, 8, 308-309.

(13) The Dialogue Continues. Nat. Nanotechnol. 2013, 8, 6969.10.1038/nnano.2013.19

(14) McCall, M. J.; Coleman, V. A.; Herrmann, J.; Kirby, J. K.; Gardner, I. R.; Brent, P. J.; Johnson, C. M. A Tiered Approach. Nat. Nanotechnol. 2013, 8, 307-308.

(15) Fadeel, B.; Savolainen, K. Broaden the Discussion. Nat. Nanotechnol. 2013, 8, 71-71.

(16) Chu, B. Laser Light Scattering: Basic Principles and Practice; Academic Press: Cambridge, MA, 1991.
(17) Powers, K. W.; Brown, S. C.; Krishna, V. B.; Wasdo, S. C.; Moudgil, B. M.; Roberts, S. M. Research Strategies for Safety Evaluation of Nanomaterials. Part VI. Characterization of Nanoscale Particles for Toxicological Evaluation. Toxicol. Sci. 2006, 90, 296-303.

(18) Bhattacharjee, S. DLS and Zeta Potential - What They Are and What They Are Not? J. Controlled Release 2016, 235, 337-351.

(19) Filipe, V.; Hawe, A.; Jiskoot, W. Critical Evaluation of Nanoparticle Tracking Analysis (NTA) by NanoSight for the Measurement of Nanoparticles and Protein Aggregates. Pharm. Res. 2010, 27, 796-810.

(20) Hondow, N.; Brydson, R.; Wang, P.; Holton, M. D.; Brown, M. R.; Rees, P.; Summers, H. D.; Brown, A. Quantitative Characterization of Nanoparticle Agglomeration within Biological Media. J. Nanopart. Res. 2014, 14, 1-15.

(21) Doak, S. H.; Griffiths, S. M.; Manshian, B.; Singh, N.; Williams, P. M.; Brown, A. P.; Jenkins, G. J. Confounding Experimental Considerations in Nanogenotoxicology. Mutagenesis 2009, 24, 285293.

(22) Guidi, P.; Nigro, M.; Bernardeschi, M.; Scarcelli, V.; Lucchesi, P.; Onida, B.; Mortera, R.; Frenzilli, G. Genotoxicity of Amorphous Silica Particles with Different Structure and Dimension in Human and Murine Cell Lines. Mutagenesis 2013, 28, 171-180.

(23) Manshian, B. B.; Soenen, S. J.; Al-Ali, A.; Brown, A.; Hondow, N.; Wills, J.; Jenkins, G. J.; Doak, S. H. Cell Type-Dependent Changes in CdSe/ZnS Quantum Dot Uptake and Toxic Endpoints. Toxicol. Sci. 2015, 144, 246-258.

(24) Moche, H.; Chevalier, D.; Barois, N.; Lorge, E.; Claude, N.; Nesslany, F. Tungsten Carbide-Cobalt as a Nanoparticulate Reference Positive Control in In Vitro Genotoxicity Assays. Toxicol. Sci. 2014, 137, 125-134.

(25) Paget, V.; Moche, H.; Kortulewski, T.; Grall, R.; Irbah, L.; Nesslany, F.; Chevillard, S. Human Cell Line-Dependent WC-Co Nanoparticle Cytotoxicity and Genotoxicity: A Key Role of ROS Production. Toxicol. Sci. 2015, 143, 385-397.

(26) Stoccoro, A.; Di Bucchianico, S.; Uboldi, C.; Coppede, F.; Ponti, J.; Placidi, C.; Blosi, M.; Ortelli, S.; Costa, A. L.; Migliore, L. A Panel of In Vitro Tests to Evaluate Genotoxic and Morphological Neoplastic Transformation Potential on Balb/3T3 Cells by Pristine and Remediated Titania and Zirconia Nanoparticles. Mutagenesis 2016, $31,511-529$.

(27) Wallace, R.; Brown, A. P.; Brydson, R.; Milne, S. J.; Hondow, N.; Wang, P. Characterisation of $\mathrm{ZnO}$ Nanoparticle Suspensions for Toxicological Applications. J. Phys. Conf. Ser. 2012, 371.01208010.1088/1742-6596/371/1/012080

(28) Bonini, M.; Rossi, S.; Karlsson, G.; Almgren, M.; Lo Nostro, P.; Baglioni, P. Self-Assembly of Beta-Cyclodextrin in Water. Part 1: CryoTEM and Dynamic and Static Light Scattering. Langmuir 2006, 22, $1478-1484$

(29) Jackson, C. L.; Chanzy, H. D.; Booy, F. P.; Drake, B. J.; Tomalia, D. A.; Bauer, B. J.; Amis, E. J. Visualization of Dendrimer Molecules by Transmission Electron Microscopy (TEM): Staining Methods and Cryo-TEM of Vitrified Solutions. Macromolecules 1998, 31, 62596265.

(30) Dutta, D.; Sundaram, S. K.; Teeguarden, J. G.; Riley, B. J.; Fifield, L. S.; Jacobs, J. M.; Addleman, S. R.; Kaysen, G. A.; Moudgil, B. M.; Weber, T. J. Adsorbed Proteins Influence the Biological Activity and Molecular Targeting of Nanomaterials. Toxicol. Sci. 2007, 100, 303-315.

(31) Organisation for Economic Cooperation and Development (OECD). Test Guideline 487 - The in Vitro Mammalian Cell Micronucleus Test. 2014, http://dx.doi.org/10.1787/9789264264861en, accessed August 15, 2017.

(32) Napierska, D.; Thomassen, L. C.; Lison, D.; Martens, J. A.; Hoet, P. H. The Nanosilica Hazard: Another Variable Entity. Part. Fibre Toxicol. 2010, 7, 39.

(33) Wills, J. W.; Hondow, N.; Thomas, A. D.; Chapman, K. E.; Fish, D.; Maffeis, T. G.; Penny, M. W.; Brown, R. A.; Jenkins, G. J. S.; Brown, A. P.; White, P. A.; Doak, S. H. Genetic Toxicity Assessment of 
Engineered Nanoparticles Using a 3D In Vitro Skin Model (EpiDerm). Part. Fibre Toxicol. 2016, 13, 50.

(34) Oliveira, C. L.; Veiga, F.; Varela, C.; Roleira, F.; Tavares, E.; Silveira, I.; Ribeiro, A. J. Characterization of Polymeric Nanoparticles for Intravenous Delivery: Focus on Stability. Colloids Surf., B 2016, $150,326-333$.

(35) Veering, B. T.; Burm, A. G.; Souverijn, J. H.; Serree, J. M.; Spierdijk, J. The Effect of Age on Serum Concentrations of Albumin and Alpha 1-Acid Glycoprotein. Br. J. Clin. Pharmacol. 1990, 29, 201206.

(36) Awdeh, Z. L.; Islam, M. R.; Abu Samra, S. Variations in the Level of Human Serum Albumin During Glucose Tolerance Test. Biochem. Biophys. Res. Commun. 1974, 56, 358-362.

(37) Schrurs, F.; Lison, D. Focusing the Research Efforts. Nat. Nanotechnol. 2012, 7, 546-548.

(38) Doak, S. H.; Manshian, B.; Jenkins, G. J.; Singh, N. In Vitro Genotoxicity Testing Strategy for Nanomaterials and the Adaptation of Current OECD Guidelines. Mutat. Res., Genet. Toxicol. Environ. Mutagen. 2012, 745, 104-111.

(39) Halamoda-Kenzaoui, B.; Ceridono, M.; Colpo, P.; Valsesia, A.; Urbán, P.; Ojea-Jiménez, I.; Gioria, S.; Gilliland, D.; Rossi, F.; KinsnerOvaskainen, A. Dispersion Behaviour of Silica Nanoparticles in Biological Media and its Influence on Cellular Uptake. PLoS One 2015, 10, e0141593.

(40) Gonzalez, L.; Sanderson, B. J.; Kirsch-Volders, M. Adaptations of the In Vitro MN Assay for the Genotoxicity Assessment of Nanomaterials. Mutagenesis 2011, 26, 185-91.

(41) Lim, J.; Yeap, S. P.; Che, H. X.; Low, S. C. Characterization of Magnetic Nanoparticle by Dynamic Light Scattering. Nanoscale Res. Lett. 2013, 8, 381.

(42) Albanese, A.; Chan, W. C. W. Effect of Gold Nanoparticle Aggregation on Cell Uptake and Toxicity. ACS Nano 2011, 5, 54785489 .

(43) Teeguarden, J. G.; Hinderliter, P. M.; Orr, G.; Thrall, B. D.; Pounds, J. G. Particokinetics In Vitro: Dosimetry Considerations for In Vitro Nanoparticle Toxicity Assessments. Toxicol. Sci. 2007, 95, 300312.

(44) Lead, J.; Holgate, S. Regulatory and Research Needs. Nat. Nanotechnol. 2013, 8, 72-72.

(45) Deguchi, S.; Yamazaki, T.; Mukai, S.-a.; Usami, R.; Horikoshi, K. Stabilization of C60 Nanoparticles by Protein Adsorption and its Implications for Toxicity Studies. Chem. Res. Toxicol. 2007, 20, 854858.

(46) Wiogo, H. T. R.; Lim, M.; Bulmus, V.; Yun, J.; Amal, R. Stabilization of Magnetic Iron Oxide Nanoparticles in Biological Media by Fetal Bovine Serum (FBS). Langmuir 2011, 27, 843-850.

(47) Berne, B. J.; Pecora, R. Dynamic Light Scattering: With Applications to Chemistry, Biology and Physics; Dover Publications: New York, 2000.

(48) Hunter, R. J. Zeta Potential in Colloidal Science: Principles and Applications; Academic Press: Cambridge MA, 1988.

(49) Cho, E. C.; Zhang, Q.; Xia, Y. The Effect of Sedimentation and Diffusion on Cellular Uptake of Gold Nanoparticles. Nat. Nanotechnol. 2011, 6, 385-391.

(50) Ware, M. J.; Godin, B.; Singh, N.; Majithia, R.; Shamsudeen, S.; Serda, R. E.; Meissner, K. E.; Rees, P.; Summers, H. D. Analysis of The Influence of Cell Heterogeneity on Nanoparticle Dose Response. ACS Nano 2014, 8, 6693-6700.

(51) Summers, H. D.; Rees, P.; Holton, M. D.; Rowan Brown, M.; Chappell, S. C.; Smith, P. J.; Errington, R. J. Statistical Analysis of Nanoparticle Dosing in a Dynamic Cellular System. Nat. Nanotechnol. 2011, 6, 170-174.

(52) Summers, H. D.; Brown, M. R.; Holton, M. D.; Tonkin, J. A.; Hondow, N.; Brown, A. P.; Brydson, R.; Rees, P. Quantification of Nanoparticle Dose and Vesicular Inheritance in Proliferating Cells. ACS Nano 2013, 7, 6129-6137.

(53) Cohen, J. M.; Teeguarden, J. G.; Demokritou, P. An Integrated Approach For the In Vitro Dosimetry of Engineered Nanomaterials. Part. Fibre Toxicol. 2014, 11, 20.
(54) DeLoid, G. M.; Cohen, J. M.; Pyrgiotakis, G.; Pirela, S. V.; Pal, A.; Liu, J.; Srebric, J.; Demokritou, P. Advanced Computational Modeling For In Vitro Nanomaterial Dosimetry. Part. Fibre Toxicol. 2015, 12, 32.

(55) DeLoid, G.; Cohen, J. M.; Darrah, T.; Derk, R.; Rojanasakul, L.; Pyrgiotakis, G.; Wohlleben, W.; Demokritou, P. Estimating the Effective Density of Engineered Nanomaterials for In Vitro Dosimetry. Nat. Commun. 2014, 5, 3514.

(56) Rasband, W. S. Imagej; U.S. National Institutes of Health: Bethesda, MD, USA, 1997-2017, http://imagej.nih.gov/ij/, accessed August 15, 2017.

(57) Arbab, A. S.; Wilson, L. B.; Ashari, P.; Jordan, E. K.; Lewis, B. K. Frank, J. A. A Model of Lysosomal Metabolism of Dextran Coated Superparamagnetic Iron Oxide (SPIO) Nanoparticles: Implications for Cellular Magnetic Resonance Imaging. NMR Biomed. 2005, 18, 383389.

(58) Messaoudil, C.; Boudier, T.; Sorzano, C. O. S.; Marco, S. TomoJ: Tomography Software for Three-Dimensional Reconstruction in Transmission Electron Microscopy. BMC Bioinf. 2007, 8, 19.10.1186/1471-2105-8-288

(59) International Organisation for Standardisation. ISO 3105:1994. Glass Capillary Kinematic Viscometers-Specifications and Operating Instructions. 1994-2012, https://www.iso.org/standard/8254.html, accessed August 15, 2017.

(60) Johnson, G. E.; Hernandez, L. G.; Gollapudi, B.; Bodger, O.; Dearfield, K.; Heflich, R.; Hixon, J.; Lovell, D.; MacGregor, J.; Pottenger, L.; Thompson, C.; Abraham, L.; Thybaud, V.; Tanir, J.; Zeiger, E.; Van Bentham, J.; White, P. A. Derivation of Point of Departure (PoD) Estimates in Genetic Toxicology Studies and Their Potential Applications in Risk Assessment. Environ. Mol. Mutagen. 2014, 55, 609-623.

(61) Avancini, D.; Menzies, G. E.; Morgan, C.; Wills, J.; Johnson, G. E.; White, P. A.; Lewis, P. D. MutAIT: an Online Genetic Toxicology Data Portal and Analysis Tools. Mutagenesis 2016, 31, 323-328.

(62) Wills, J. W.; Johnson, G. E.; Doak, S. H.; Soeteman-Hernandez, L. G.; Slob, W.; White, P. A. Empirical Analysis of BMD Metrics in Genetic Toxicology Part I: In Vitro Analyses to Provide Robust Potency Rankings and Support MOA Determinations. Mutagenesis 2016, 31, 255-263.

(63) Wills, J. W.; Long, A. S.; Johnson, G. E.; Bemis, J. C.; Dertinger, S. D.; Slob, W.; White, P. A. Empirical Analysis of BMD Metrics in Genetic Toxicology Part II: In Vivo Potency Comparisons to Promote Reductions in the Use of Experimental Animals for Genetic Toxicity Assessment. Mutagenesis 2016, 31, 265-275.

(64) European Food Safety Authority (EFSA). Guidance of the Scientific Committee on Use of the Benchmark Dose Approach in Risk Assessment. EFSA Journal 2009, 1150, 1-72.

(65) European Food Safety Authority (EFSA). Update: Guidance on the Use of the Benchmark Dose Approach in Risk Assessment. EFSA Journal. 2017, 15, 4658-4699.

(66) Slob, W. Dose-Response Modeling of Continuous Endpoints. Toxicol. Sci. 2002, 66, 298-312.

(67) Kienhuis, A. S.; Slob, W.; Gremmer, E. R.; Vermeulen, J. P.; Ezendam, J. A Dose-Response Modeling Approach Shows that Effects from Mixture Exposure to the Skin Sensitizers Isoeugenol and Cinnamal are In Line with Dose Addition and not with Synergism. Toxicol. Sci. 2015, 147, 68-74. 